NBER WORKING PAPER SERIES

\title{
THE RIGHT TYPE OF LEGISLATOR: A THEORY OF TAXATION AND REPRESENTATION
}

\author{
Andrea Mattozzi \\ Erik Snowberg \\ Working Paper 24279 \\ http://www.nber.org/papers/w24279 \\ NATIONAL BUREAU OF ECONOMIC RESEARCH \\ 1050 Massachusetts Avenue \\ Cambridge, MA 02138 \\ February 2018
}

Snowberg gratefully acknowledges the support of NSF SES-1156154. We thank Ethan Bueno de Mesquita, Josh Clinton, Stephen Coate, Daniel Diermeier, Tim Feddersen, Patrick Francois, Sean Gailmard, Andrea Galeotti, Alex Hirsch, Morgan Kousser, Kai Konrad, Jenny Mansbridge, Gerard Padrl'o i Miquel, Pablo Montagnes, Salvatore Nunnari, Giacomo Ponzetto, Debraj Ray, Jean-Laurent Rosenthal, Allistair Smith, Ken Shotts, Jim Snyder, Francesco Trebbi, Leeat Yariv, and seminar audiences at the Priorat Workshop, the Rotterdam Workshop in Political Economy, WZB Berlin, the Chicago Workshop on Institutional Design, the CIRPEE Political Economy conference, the Collegio Carlo Alberto, MPSA, Caltech, the University of Miami, IPEG, MEDS, George Mason, Georgetown, UBC, and UCB for useful conversations, comments, and encouragement. We also thank the Casa del Popolo di Fiesole for their hospitality, although it may have been reduced had they known what we were writing. The views expressed herein are those of the authors and do not necessarily reflect the views of the National Bureau of Economic Research.

NBER working papers are circulated for discussion and comment purposes. They have not been peer-reviewed or been subject to the review by the NBER Board of Directors that accompanies official NBER publications.

(C) 2018 by Andrea Mattozzi and Erik Snowberg. All rights reserved. Short sections of text, not to exceed two paragraphs, may be quoted without explicit permission provided that full credit, including $(\odot$ notice, is given to the source. 
The Right Type of Legislator: A Theory of Taxation and Representation

Andrea Mattozzi and Erik Snowberg

NBER Working Paper No. 24279

February 2018

JEL No. D72,D78,H10,H23

\begin{abstract}
$\underline{\text { ABSTRACT }}$
We develop a theory of taxation and the distribution of government spending in a citizencandidate model of legislatures. Individuals are heterogeneous in two dimensions: productive ability in the private sector and negotiating ability in politics. When these are positively correlated, rich voters always prefer a rich legislator, but poor voters face a trade-off. A rich legislator will secure more pork for the district, but will also prefer lower taxation than the poor voter. Our theory organizes a number of stylized facts across countries about taxation and redistribution, parties, and class representation in legislatures. We demonstrate that spending does not necessarily increase when the number of legislators increases, as the standard common-pool intuition suggests, and that many policies aimed at increasing descriptive representation may have the opposite effect.
\end{abstract}

\author{
Andrea Mattozzi \\ European University Institute \\ Department of Economics \\ Villa La Fonte \\ Via delle Fontanelle 18 \\ 50014 San Domenico di Fiesole \\ Italy \\ Andrea.Mattozzi@EUI.eu \\ Erik Snowberg \\ Division of Humanities and Social Sciences \\ MC 228-77 \\ California Institute of Technology \\ Pasadena, CA 91125 \\ and NBER \\ snowberg@caltech.edu
}




\section{Introduction}

The determination of economic policies, such as tax regimes, is of central importance to economic inquiry. In seminal models of distributive politics, legislators are viewed as independent actors mainly interested in directing public funds to their district at the expense of the general population (Tullock, 1959; Weingast, 1979; Weingast, Shepsle and Johnsen, 1981). Legislators' desire to bring "pork" to their districts results in a common pool problem, leading to higher spending, and thus, taxation. This mechanism is a fundamental component of the way the existing theoretical literature has modeled fiscal policy outcomes in representative democracies.

The main drawback of this approach is that it is at odds with what is seen across developed countries. In particular, the U.S. has relatively low taxes even though successfully delivering pork is an important part of a legislator's job. In contrast, European countries, such as the U.K., Italy, or Germany, have higher taxes despite the fact that legislators largely do not compete for pork 1 Further, the literature investigating the empirical relation between the severity of the common pool problem (measured by the size of the legislature) and the size of government is inconclusive, with a number of papers finding a negative relationship.2

In this paper, we reconcile the common pool logic with the above stylized facts, and generate a number of additional testable predictions. We do so by introducing the abilities and personal preferences of legislators into the model. Specifically, we combine workhorse models with a simple assumption: individuals who are more successful in the private sector will tend to be more successful, as legislators, at directing resources back to their district. This assumption can be summarized simply as: whatever gets one ahead in the private

\footnotetext{
${ }^{1}$ U.S. taxes at all levels of government equaled $26 \%$ of GDP in 2015. This number is well below the $36 \%$ for the U.K., $37 \%$ for Germany, and $43 \%$ for Italy. See, for example, taxpolicycenter.org/briefing-book/howdo-us-taxes-compare-internationally. Hix and Noury (2016) analyzes roll-call voting data from 16 legislatures and shows that voting behavior follows government-opposition interests, rather than individual members' or parties' policy positions, and concludes that "voting in most legislatures is more like Westminster than Washington." As there is little competition for pork in the U.K., this suggests very little competition for pork in European legislatures.

${ }^{2}$ For a review of the theoretical and empirical literature on the so-called "Law of $1 / \mathrm{n}$ " see Primo and Snyder (2008). Pettersson-Lidbom (2012) is one of the cleanest tests, and finds a negative relationship between spending and the number of legislators.
} 
sector - for example, connections, hard work, charisma - is also useful, on average, in negotiating resources for one's district. We refer to these skills, as a group, as negotiating skills. This is in contrast to recent work - reviewed in Section 1.2 that has largely abandoned the common pool mechanism, and instead argues that cross-countries differences in tax regimes are the result of differences in the political system, the electoral rule, or culture.

Our results are useful for organizing a number of stylized facts about differences in taxation, redistribution, and representation across developed countries. Our model and assumption together imply that the rich will be overrepresented in all legislatures. It further suggests that the U.S. will have wealthier legislators, lower taxes, and parties that are less differentiated on the size of government than Western European countries. Moreover, our findings are consistent with the fact that, in the U.S., individual legislators will be popular in their districts, while the legislature itself is quite unpopular. Additionally, our model can be used to derive implications about descriptive representation, in particular, that women will be more under-represented in the U.S. than in Western Europe.

\subsection{Theoretical Argument}

Before delineating the specifics of our model, it is worth discussing, in broad conceptual terms, how our central assumption leads to the predictions above. In contrast with standard models, which assume every legislator has equal ability to bring pork back to his district, we allow for heterogeneity in that skill $\mathrm{I}^{3}$ This may create a trade-off for voters: they may prefer someone they think is more able to bring pork to their district over someone who perfectly shares their preferences. If these abilities are correlated with particular preferences, this will naturally lead to over-representation of these preferences in the legislature and policy. The specific assumption we consider seems quite natural: the ability to generate private sector value (income) and public sector value (pork) are correlated, and thus also correlated with preferences for low taxes (to protect their high incomes). This will lead to an over-

\footnotetext{
${ }^{3}$ We follow the principal-agent literature in referring to legislators (agents) using masculine pronouns, and citizens (principals) — especially the median voter of a district — using feminine pronouns.
} 
representation of low-tax preferences in legislatures, even if the correlation in abilities is imperfect (Section 4.1), or if the correlation does not actually exist, but voters perceive that it does (Section 5.1).

Our instantiation of the above logic allows for redistribution both between the rich and the poor, and between legislative districts. Citizen voting follows standard median-voter logic (Downs, 1957; Hotelling, 1929; Meltzer and Richard, 1981). Once elected, legislators participate in a two-stage budgeting process where they first vote on taxes using majority rule, and then negotiate over the distribution of the budget Chari, Jones and Marimon, 1997; Persson, Roland and Tabellini, 1997). Because we assume legislators are citizen candidates, their actions in office follow their own preferences $4^{4}$ Citizens are one of two types: rich or poor. Our central assumption is that the rich have relatively high negotiating skills, and the poor have relatively low negotiating skills.

The main tradeoff that our model highlights is simple and robust: a district's legislator, as one of many in the legislature, has little impact on broad policies, such as the tax rate, but a relatively large impact on the transfers that the district receives. Knowing this, even the median voter of a poor district will ignore a candidate's preferences over redistribution and focus on his negotiating skills, that is, a rich candidate's superior ability to direct transfers to his district. A more subtle intuition comes from seeing the game that voters play as a prisoner's dilemma: all poor voters voting for poor legislators would make all poor voters better off. However, it is strictly dominant for an individual poor voter to choose a successful-that is, rich-legislator.

This model yields a striking result: when securing resources for one's district is important, then, in equilibrium, every district votes for candidates who are successful in the private sector - that is, rich. This occurs even though those candidates prefer lower taxeswhich they actualize - than voters, and despite the fact that everyone elects equally effective

\footnotetext{
${ }^{4}$ This is implicit in the citizen-candidate framework of Osborne and Slivinski (1996) and Besley and Coate (1997), and can be relaxed. See Sections 4.3, 4.1, and 7, This is consistent with the selection model of Miller and Stokes (1963), especially as elucidated by Mansbridge (2009). A focus on candidate preferences is rationalizable: Fearon (1999) finds that voters are better off using elections to select types, rather than disciplining incumbents.
} 
negotiators, so the spending in all districts is equal.

The equilibrium exhibits three patterns of representation. When ability to direct funds to a legislator's own district does not matter at all - say through budgeting procedures that make it impossible to target funding - then every district elects a legislator who is the same type as its median voter, and the tax rate is effectively set by the median voter of the median district. We call this a representative equilibrium. If, instead, ability to direct funds matters just a little, many districts with poor median voters will elect rich legislators. However, poor legislators will still form a minimal winning coalition in the legislature. Those that vote for rich legislators will know, in equilibrium, that they will not cause the legislature to tip to a rich majority, and hence will choose a rich legislator for his superior negotiating abilities. The legislative majority, composed of poor legislators, knows that rich legislators will get more than an equal share of tax revenues, and will shade down the tax rate to reduce the expropriation from their districts. We call such equilibria somewhat representative. Finally, when the ability to direct funds to a legislator's own district is important, then the unique equilibrium will be for every district to elect a rich legislator. This unrepresentative equilibrium occurs due to the logic laid out above.

\section{$1.2 \quad$ Literature}

A large literature argues that tax regimes are largely explained by voting systems and rules, in particular by differences between plurality rule and proportional representation (see Persson and Tabellini, 2000, for a review). While these explanations capture important aspects of variation in tax regimes for countries with markedly different rules, they are less compelling for countries that are relatively more similar, such as the U.S. and U.K., which both elect legislators through plurality rule. We instead focus on how differences in opportunities for distributional spending affects the preferences of those elected, and thus, policy. Our paper contributes to a literature examining heterogeneity in political skills and its potential effect on redistributive policies. Following Stokes s (1963) influential critique of the Downsian model, this literature tries to understand the causes and consequences the "ability" of politicians. 
Theory papers in this tradition tend to assume that the ability of a politician is a draw from a distribution (for example, Groseclose, 2001), while empirical papers consider education or prior income as markers of quality (for example, Gagliarducci and Nannicini, 2013) !5 Instead, we consider a specific ability - the ability to negotiate resources for their districtand assume that this ability is correlated with private sector success ${ }^{6}$

In our theory, we explicitly consider the interaction between different legislative districts, and how this alters voters' preferences over politicians. While the mechanism we uncover is novel, the existence of a tension between candidates' preferences and their ability to implement certain policies is documented elsewhere (Besley and Coate, 1997; Harstad, 2010; Volden and Wiseman, 2007; Christiansen, 2013; Huber and Ting, 2013).7 Within this literature, the closest paper to ours is Huber and Ting (2013). It primarily focuses on when people "cross over" party lines in their voting. This work shares with ours the equilibrium feature that poor voters may vote for rich candidates who prefer a low tax rate $8^{8}$ However, their explanation relies on parties that can exclude districts from receiving funds. The poor then vote for the rich party in order to avoid being excluded from the legislative majority. It is worth noting that their assumption relies on powers there is little evidence that parties have. For example, heterogeneity in federal spending across districts is not well explained by the party of the legislator (Boone, Dube and Kaplan, 2014). More generally, the idea that pork distribution in the U.S. can be very unequal between parties is supported by little

\footnotetext{
${ }^{5}$ Recent research has focused on identifying more direct measures of quality, see, for example Galasso et al. (2010), Volden and Wiseman (2014), and Dal Bo et al. (2017).

${ }^{\circ}$ Most papers in this literature focus on why poor quality politicians are elected, including Caselli and Morelli (2004), Messner and Polborn (2004), Mattozzi and Merlo (2008). Appendix B.2 compares results with a model where those that are successful in the private sector have a generic ability to improve the efficiency of policy.

${ }^{7} \mathrm{~A}$ number of papers describe strategic delegation motives for voters electing politicians different from themselves. Harstad (2010) considers the trade-off between electing a conservative legislator who is a better negotiator, and electing a progressive legislator who is more likely to be included in the governing coalition. Christiansen (2013) extends the legislative bargaining framework of Volden and Wiseman (2007) by including an election stage, and shows that when voters' preferences toward pork are relatively weak, strategic delegation occurs. In addition, Besley and Coate (1997) explores the efficiency consequences of limiting the set of people (preferences) to whom voters can strategically delegate.

${ }^{8}$ In the presence of preference heterogeneity arising from different ethnic groups, Fernández and Levy (2008) show that poor voters may choose to support conservative parties that propose a mix of redistribution and targeted transfer.
} 
empirical evidence $?^{9}$ Furthermore, in Huber and Ting (2013), coordination could benefit either the party of the rich or the party of the poor. That is, the rich may vote for the party of the poor and high taxes to ensure they are not left out of the governing coalition.

Closely related to this phenomena, and, in particular, to why many U.S. voters appear to vote against their economic interest, is the debate about whether or not there is a wealth bias in U.S. politics (Frank, 2004; Bartels, 2007; Gilens and Page, 2014). To develop our formaltheoretic basis for why poorer voters would choose to be represented by wealthy legislators with policy preferences different from theirs, we build on Carnes's (2013) empirical findings showing that legislators from higher socio-economic status professions have more conservative voting records. Our explanation is complementary to explanations that focus on differences in campaign resources (Campante, 2011) and the sensitivity of poor voters to the outcomes of richer voters (Bartels, 2007).

\section{Model}

The structure of our model, and the players these structures contain are:

Legislative Districts: We model a country populated with a unit measure of citizens, and with $2 n+1$ legislative districts $j \in J=\{1,2, \ldots, 2 n+1\}$, each containing an equal measure of citizens.

Citizens: A citizen's utility includes post-tax income and utility from government spending in her district. A citizen's pre-tax income is determined solely by her publicly observable type, $t \in\{l, h\}$, which is either low or high. The income of a low type is $y_{l}$, and the income

\footnotetext{
${ }^{9}$ There is considerable empirical evidence in the pork-barrel politics literature that points to "[U]niversalism and reciprocity [being] the prevailing decision rules in the U.S. Congress." (Weingast, 1979 , p. 353). See also Weingast (1994). More recently, Berry and Fowler (2016) finds that Members of Congress holding seats on key committees are not particularly successful in bringing more federal funds to their districts, with the only exception being chairs of Appropriations subcommittees. While Berry, Burden and Howell (2010) finds that districts receive more federal funds when their legislators are allied with the president's party, Dynes and Huber (2015) shows that there is little evidence that presidents favor areas represented by their party in the House.
} 
of a high type is $y_{h}=\eta y_{l}$, with $\eta \in(1, \bar{\eta})$ parameterizing the productivity difference between high types and low types. We occasionally refer to high types as rich or successful, and low types as poor or unsuccessful. Overall, a fraction $\lambda \in(1 / 2,1)$ of citizens are low types, so the total income of all legislative districts together is given by $\bar{y} \equiv(\lambda+(1-\lambda) \eta) y_{l}$. We restrict the tax instrument $\tau$ to be linear in income, thus tax revenue is given by $\tau \bar{y} .10$

District $j$ receives a proportion $\pi_{-j}^{j}$ of tax revenues, which is determined by the type of legislator elected in $j$ 's district, as well as the other $(-j)$ districts. Section 2.2.1 describes the specific process determining this distribution. The utility that each individual receives from $x$ amount of local government spending is $g(x)=x^{\alpha} / \alpha$ with $\alpha \in(0,1)$. Given the above, we can write the utility of an individual voter as:

$$
u_{i j}=(1-\tau) y^{i}+\frac{\left(\pi_{-j}^{j} \tau \bar{y}\right)^{\alpha}}{\alpha}
$$

When an equal proportion of tax revenues is transferred to each district $\pi_{-j}^{j}=1 /(2 n+1)$, and we denote by $\tau_{l}^{*}$ and $\tau_{h}^{*}$ the most-preferred tax rates of low and high types, respectively:

$$
\tau_{l}^{*}=\left(\frac{\bar{y}}{(2 n+1) y_{l}^{\frac{1}{\alpha}}}\right)^{\frac{\alpha}{1-\alpha}} \quad \text { and } \quad \tau_{h}^{*}=\left(\frac{\bar{y}}{(2 n+1)\left(\eta y_{l}\right)^{\frac{1}{\alpha}}}\right)^{\frac{\alpha}{1-\alpha}}=\frac{\tau_{l}^{*}}{\eta^{\frac{1}{1-\alpha}}}<\tau_{l}^{*}
$$

To guarantee $\tau_{l}^{*}<1$, we assume that $(2 n+1) y_{l}>\bar{y}^{\alpha}$. Finally, we denote by $u_{l}(\tau)$ the utility a low type receives from a given tax rate $\tau$ when tax revenues are divided equally between districts.

Legislators: Legislators are citizen candidates, implying that their actions in office are determined solely by their preferences as citizens. Initially, we assume that two candidates run in each district, a low type and a high type. Later, we endogenize candidate selection by adding parties. As types are publicly known, voters know what each candidate will do if elected, and vote accordingly. ${ }^{11}$

\footnotetext{
${ }^{10}$ Section 7 briefly discusses more complex tax instruments.

${ }^{11} \mathrm{~A}$ central assumption of the citizen-candidate model is that candidates are committed to implementing their own most-preferred policy once in office. We informally discuss relaxing this assumption in Section 4.3 .
} 
Median Voters: Using standard results, the winning candidate will be chosen by the median voter of each district. A number $z \equiv\lfloor(1-\lambda)(2 n+1)\rfloor \in\{0,1, \ldots, n\}$ of districts have a high-type median voter. By making the proportion of high-type median voters roughly equivalent to the proportion of high types in the population, we eliminate the effect of the boundaries of districts on representation (Chen and Rodden, 2013).

\section{$2.1 \quad$ Equilibrium}

We focus on subgame perfect equilibria, and establish an equilibrium concept, stage-strong, to judge the robustness of equilibria to coordinated deviations of multiple legislative districts.

Definition 1. An equilibrium is a pure-strategy, subgame-perfect Nash equilibrium in which voters play weakly-undominated strategies. A stage-strong equilibrium is an equilibrium where there are no joint deviations within a single stage of the game that make all deviating players weakly better off, and at least one player strictly better off. ${ }^{12}$

The assumption that voters play weakly-undominated strategies means we can simply examine the strategies of the median voters of each district. The equilibria of this model can be of three types:

\section{Definition 2.}

1. We say an equilibrium is representative if the tax rate is the same as the most preferred tax rate of the median voter of the median district, $\tau_{l}^{*}$.

2. We say an equilibrium is somewhat representative if there is an over-representation of high types in the legislature, and the equilibrium tax rate is $\tau \in\left(\tau_{h}^{*}, \tau_{l}^{*}\right)$.

3. We say an equilibrium is unrepresentative if all districts elect high-type legislators, and the tax rate is that most preferred by a high-type citizen, $\tau_{h}^{*} 13$

\footnotetext{
${ }^{12}$ In our environment, there will be no strong Nash equilibria, but the deviations that prevent such equilibria from occurring are not sequentially rational. On the other hand, unique equilibria are always coalitionproof (Bernheim, Peleg and Whinston, 1987, Bernheim and Whinston, 1987). Stage-strong equilibria are thus more robust to deviations than coalition-proof equilibria, but impose that deviations be sequentially rational.

${ }^{13}$ We do not conduct welfare analyses, as these depend critically on assumptions about the distortionary effects of taxation. That is, there exists some level of distortion such that any of these equilibria structures may be welfare maximizing.
} 


\subsection{Timeline}

Our model of elections and legislative policymaking proceeds in three stages. These are:

1. The voting stage. Voters simultaneously vote for one of two citizen candidates based on the utility they expect to receive with each candidate as their representative in the legislature. Thus, their votes will depend on the candidates' types, and the types of candidates elected by the other legislative districts.

2. The tax-policy stage. Legislators vote on a level of taxes using an open rule. In subgame perfect equilibria, legislators will take into account what will happen in the distributive stage. As the majority of the legislature will always be of the same type, they will have the same most-preferred tax rate, which will be adopted.

3. The distributive stage. Distribution of the public budget among districts is determined by a negotiating process described in Section 2.2.1.

After the distribution stage, incomes are realized, taxes are levied, and tax revenue is distributed according to the decisions described above. We describe these stages in more detail below.

\subsubsection{The Distributive Stage}

Taking advantage of the fact that subgame perfect equilibria can be found through backwards induction, we start by defining outcomes in the third, distributive, stage.

As noted above, each district receives public transfers funded by a linear tax on income. High types are advantaged in negotiating transfers for their district by the same proportion as their increase in productivity in the private sector: $\eta$. Section 4.1 discusses the case when negotiating ability and preferences for redistribution are imperfectly correlated.

A high type's advantage may be mitigated by institutional features. In particular, $1-\gamma \in$ 
$[0,1]$ parameterizes the degree to which a high type's negotiating ability is restricted $\sqrt[14]{4}$ The proportion of tax revenues a district receives takes on six values that are relevant for the analysis. We define these as:

$$
\begin{gathered}
\pi_{(2 n+1) L}^{L}=\frac{1}{2 n+1}, \\
\pi_{(n+1) L}^{L}=\frac{1}{n((1-\gamma)+\gamma \eta)+(n+1)}<\frac{1}{2 n+1}, \quad \pi_{(n+1) L}^{H}=\frac{(1-\gamma)+\gamma \eta}{n((1-\gamma)+\gamma \eta)+(n+1)}>\frac{1}{2 n+1}, \\
\pi_{(n+1) H}^{L}=\frac{1}{(n+1)((1-\gamma)+\gamma \eta)+n}<\frac{1}{2 n+1}, \quad \pi_{(n+1) H}^{H}=\frac{(1-\gamma)+\gamma \eta}{(n+1)((1-\gamma)+\gamma \eta)+n}>\frac{1}{2 n+1}, \\
\text { and } \pi_{(2 n+1) H}^{H}=\frac{1}{2 n+1},
\end{gathered}
$$

where the subscript displays the number and type of legislators in the legislative majority, and the superscript defines whether district $j$ is represented by a high-type or low-type legislator. Note that the denominator changes to ensure that the sum of proportions always equals one.

The most important way in which our model departs from previous work is the existence of different abilities for negotiating transfers to a legislator's district. The parameter $\gamma$ dictates the extent to which negotiating ability matters. If $\gamma$ is low, then most funds are simply divided evenly between districts, and a legislator's type will matter very little for the amount of transfers a district will receive. On the other hand, when $\gamma$ is high, a legislator's type may matters quite a lot. Thus, $1-\gamma$ can be thought of as any institutional features that limit the competition between legislators, or reduce the amount of tax revenue a hightype legislator can negotiate for his district. For example, the ability to target only to broad demographic groups, rather than to narrow geographic areas, would result in a lower $\gamma$. How

\footnotetext{
${ }^{14}$ Formally, the share of tax revenue that is returned to district $j$ is given by:
}

$$
\pi^{j} \propto \begin{cases}(1-\gamma)+\gamma * 1 & \text { if legislator } j \text { is a low type } \\ (1-\gamma)+\gamma * \eta & \text { if legislator } j \text { is a high type }\end{cases}
$$

Solving this system of equations produces the values in the text. This particular form can be motivated by the Baron and Ferejohn (1989) legislative bargaining model, see Appendix B.4. However, modeling this explicitly makes outcomes risky from the perspective of the voter, which, given the concavity of the utility of public spending, will lead to effects that obscure the main intuition driving our result without qualitatively affecting it. 
institutional features shape $\gamma$ and the nature of representation is the subject of extensive discussion in Section 6 .

\subsubsection{The Tax-Policy and Voting Stages}

Given the outcome of the distributive stage, the first two stages are governed by standard median voter results. In the tax-policy stage, tax preferences will depend on a legislator's type and the types of the other legislators. However, there will always be at least $n+1$ legislators who are the same type - and face the same other types in the legislature - and thus will end up with the same most-preferred tax rate. These legislators will vote together to establish the tax rate.

Knowing these outcomes, voters will vote for the candidate they believe will maximize their utility through taxes and negotiated government spending in their district, taking into account the electoral choices in other districts.

\section{Analysis}

The analysis of the model proceeds here in three steps. First, we characterize all equilibria. Second, we examine the roll of $\gamma$ by focusing on an example using three districts $(n=1)$. As $\gamma$ grows, the payoffs to low-type median voters resemble a prisoner's dilemma; thus, they

all defect to electing a high-type legislator. Third, we examine the common pool logic by describing how the equilibria change with $n$. As $n$ grows, an individual legislator's effect on the tax rate decreases, while his impact on transfers to his district stays relatively constant. Thus, as it will be clear in the Section 3.3, the unrepresentative equilibrium is unique for lower values of $\gamma$.

\subsection{Central Result}

Our central result shows that when legislators' ability to negotiate spending for their district does not matter, fairly standard results apply. However, when this ability is important, no 
Figure 1: Equilibrium structure depends on the value of $\gamma$.

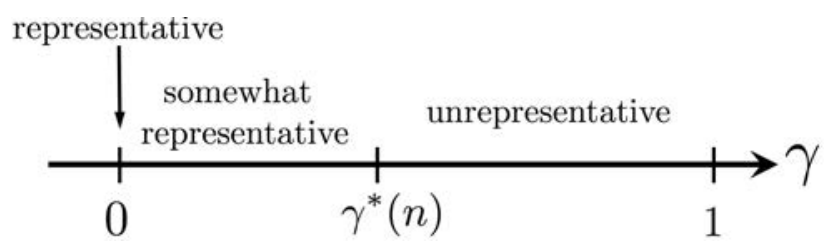

district wants to reduce their transfers by electing a low-type legislator, and thus, only hightype legislators will be elected in equilibrium. Because high-type legislators are richer, they have a personal preference for lower taxation, which results in a lower level of equilibrium redistribution than low-type voters would like.

\section{Proposition 1.}

1. If $\gamma=0$, then every equilibrium is representative with tax rate $\tau_{l}^{*}$, and all districts receive an equal proportion of the tax revenues.

2. If $0<\gamma<\gamma^{*}(n)<1$ there are two types of equilibria:

(a) Unrepresentative equilibria, with the legislature composed of all high types, and tax rate $\tau_{h}^{*}$. These equilibria are not stage strong.

(b) Somewhat representative, with the legislature composed of $n+1$ low types and $n$ high types, and tax rate $\left[(2 n+1) \pi_{(n+1) L}^{L}\right]^{\frac{\alpha}{1-\alpha}} \tau_{l}^{*}<\tau_{l}^{*}$.

3. If $\gamma^{*}(n)<\gamma<1$ then the unique equilibrium is unrepresentative with tax rate $\tau_{h}^{*}$, and all districts receive an equal proportion of the tax revenues.

If $\frac{z}{2 n+1}>\frac{1}{\gamma(\eta-1)}\left(\eta^{\frac{1}{\alpha}}\left(\frac{1-\alpha}{\eta-\alpha}\right)^{\frac{1-\alpha}{\alpha}}-1\right)$ this equilibrium is stage strong.

Where $\gamma^{*}(n)$ is defined implicitly from the following relationship

$$
\gamma<\gamma^{*}(n) \Longleftrightarrow\left(\frac{\pi_{(n+1) H}^{H}}{\pi_{(n+1) L}^{L}}\right)^{\frac{\alpha}{1-\alpha}}<\frac{u_{l}\left(\tau_{l}^{*}\right)-y_{l}}{u_{l}\left(\tau_{h}^{*}\right)-y_{l}},
$$

which is central to the analysis that follows.

We now turn to a detailed construction of this result where we can isolate the effects of negotiating ability $(\gamma)$ and of the number of districts $(n)$.

\subsection{Example: Three Districts}


We first examine the case when $n=1$, that is, when there are three legislative districts. This helps elucidate how differences in negotiating ability affect our results, and builds the prisoner's dilemma intuition behind Proposition 1 .

\subsubsection{Representative Equilibrium}

When $\gamma=0$, then (3) simplifies to $\pi_{3 L}=\pi_{2 L}^{L}=\pi_{2 L}^{H}=\pi_{2 H}^{L}=\pi_{2 H}^{H}=\pi_{3 H}=1 / 3$. That is, no matter what type of legislator a district elects, it will receive the same amount of the tax revenue. Thus, the median voter in each district will focus on the effect that her legislator will have on the tax rate. As such, median voters choose to elect someone who favors exactly the same tax rate that they do.

The more interesting cases are the stage-strong equilibria when $\gamma>0$.

\subsubsection{Building the Central Result with Negotiation}

When $\gamma>0$ there is the potential for redistribution not just between rich and poor, but also between districts. This changes incentives for low-type median voters. As described in Table 1, if both the other districts are electing a high type, a low-type median voter will want to elect a high type as well, leading to the first equilibrium in Part 2 of Proposition 1. However, this equilibrium is not stage strong. Specifically, if two districts with low-type median voters deviated to elect low-type legislators, these districts would be strictly better off. When $\gamma<\gamma^{*}(n)$ holds, this deviation is also an equilibrium, and it is stage strong. However, when $\gamma>\gamma^{*}(n)$, then this cannot be sustained as an equilibrium, as each low-type median voter is made strictly better off by electing a high type, no matter who the other median voter elects. Thus, each low-type median voter is caught in a prisoner's dilemma, and defects to electing a high-type legislator.

The Legislative Stages: The outcome of the distributive stage is determined by the types of the three legislators, according to (3). As we focus on subgame perfect equilibria, the legislators will take this expected distribution into account when voting on the tax rate. If 
the legislature is composed either entirely of high types or entirely of low types, then all three districts will receive the same proportion of tax revenue $\pi_{j}=1 / 3$ for all $j$. Thus, $\tau_{3 L}^{*}=\tau_{l}^{*}$, and $\tau_{3 H}^{*}=\tau_{h}^{*}$, which are the ideal tax rates of high- and low-type citizens, respectively. The legislative majority could also consist of two low types or two high types, which leads to two other potential values of the tax rate in equilibrium,

$$
\tau_{2 L}^{*} \equiv\left(3 \pi_{2 L}^{L}\right)^{\frac{\alpha}{1-\alpha}} \tau_{l}^{*} \quad \text { and } \quad \tau_{2 H}^{*} \equiv\left(3 \pi_{2 H}^{H}\right)^{\frac{\alpha}{1-\alpha}} \tau_{h}^{*}
$$

respectively. Note that as $\pi_{2 H}^{H}>\pi_{3 H}^{H}=\frac{1}{3}, \tau_{2 H}^{*}>\tau_{h}^{*}$, and as $\pi_{2 L}^{L}<\pi_{3 L}^{L}=\frac{1}{3}, \tau_{2 L}^{*}<\tau_{l}^{*}$. Thus, in equilibrium, $\tau_{h}^{*}<\tau_{2 H}^{*}<\tau_{2 L}^{*}<\tau_{l}^{*} 15$

The Election Stage: The utility of a median voter in a given district will depend on the types of the legislators elected from all three districts - see (3) and (5). It is thus useful to examine what type of legislator a median voter would want to elect, given the types of legislators elected from the other two districts. As, in equilibrium, a voter's beliefs about the types of the legislators elected by other districts must be correct, these preferences will shape the median voter's vote choice.

The preferences of median voters, conditional on the types elected in other districts, are summarized in Table 1. A high-type median voter will always want to elect a high type, as, from her perspective, there is no strategic delegation problem. A low-type median voter will also want to elect a high-type legislator whenever the other two legislative districts both elect high types or both elect low types, as the median voter's choice will not affect tax rates much, and they will get a larger portion of tax revenue.

The crucial conflict occurs when a low-type median voter is pivotal in determining the majority type in the legislature. In this case, she must weigh the benefits of a high type's ability to direct resources to her district - the left-hand side of (6) - against the cost of allowing high types to set the tax rate - the right-hand side of (6). This inequality is the

\footnotetext{
${ }^{15} \tau_{2 H}^{*}<\tau_{2 L}^{*}$ follows from $\gamma<\gamma^{*}$. When $\gamma>\gamma^{*}$ the opposite may hold. However, when that is the case, these tax rates are not relevant to the analysis.
} 
Table 1: Median Voter Incentives

\begin{tabular}{lcc}
\hline \hline $\begin{array}{l}\text { If the other two } \\
\text { districts elect }\end{array}$ & $\begin{array}{c}\text { A low-type median voter } \\
\text { will want to elect a }\end{array}$ & $\begin{array}{c}\text { A high-type median voter } \\
\text { will want to elect a }\end{array}$ \\
\hline hwo low types: & high type type \\
low type if: & high type \\
A low type & $\left(\frac{\pi_{2 H}^{H}}{\pi_{2 L}^{L}}\right)^{\frac{\alpha}{1-\alpha}} \leq \frac{u_{l}\left(\tau_{l}^{*}\right)-y_{l}}{u_{l}\left(\tau_{h}^{*}\right)-y_{l}},(6)$ & high type \\
otherwise, a high type & \\
hwo high types: &
\end{tabular}

same as (4) for $n=1$, and is crucial in understanding the unrepresentative equilibrium. When it fails to hold, a low-type median voter will not want to elect a low-type legislator, even when she knows her choice will be pivotal in determining the majority type in the legislature. Thus, districts with low-type median voters are in a prisoner's dilemma: they cannot commit to each other to both elect low types - even if one or two followed through, the others would be strictly better off electing a high type.

\subsubsection{Regional Disparities}

It is worthwhile stressing that in equilibrium the money transferred to each district will always be relatively equal. In the representative equilibrium, transfers are equal because $\gamma=0$. In the unrepresentative equilibrium, all districts elect high types, leading to equal transfers. In the somewhat representative equilibria, transfers may be unequal, but they will be similar, as these equilibria only obtain for low values of $\gamma$, which is when high types have the smallest advantage in negotiating transfers for their districts. This is consistent with a 
number of findings in the empirical literature showing that pork distribution in the U.S. is fairly equal between parties ${ }^{16}$

\subsection{The Common Pool}

As pointed out in the introduction, a central question in the literature on fiscal policy is how taxing and spending evolve as the size of the legislature grows. In this respect, our model delivers an anti-common pool result, which appears to be consistent with a number of empirical findings ${ }^{17}$ To establish this, we examine how taxing and spending evolve as the size of the legislature $n$ grows. When this occurs, the effect of a legislator's ability to negotiate resources for his district is relatively constant, while his effect on tax policy shrinks. As such, low types want to elect high-type legislators even if $\gamma$ is relatively low.

Recall that there are $z \leq n$ high-type median voters. These voters will always elect a high-type legislator. Thus, when (4) holds, $n-z$ low-type median voters will elect high-type legislators. This makes the remaining $n+1$ low-type median voters pivotal, so they will prefer to elect a low-type legislator. On the other-hand, if (4) does not hold, then low-type median voters always wish to elect high-type legislators, no matter who is elected in every other district. As electing a low-type legislator is strictly dominated, the unique equilibrium will be for every district to elect a high-type legislator.

To understand how (4) depends on $n$, note that the right-hand side can be reduced to

$\frac{\eta^{\frac{1}{1-\alpha}}(1-\alpha)}{\eta-\alpha}$, which is constant in $n$. However, the left-hand side is increasing in $n$. Thus, holding $\gamma>0$ constant, as $n$ grows there is a point where the equilibrium switches from a somewhat representative equilibrium to the unrepresentative equilibrium. Defining $\tau_{n}^{*}$ as the tax rate implemented when there are $2 n+1$ legislators, we have:

\footnotetext{
${ }^{16}$ See the discussion in Section 1.2

${ }^{17}$ See the review in Primo and Snyder (2008).
} 
Figure 2: The Anti-Common Pool: Tax rates decrease with $n$.

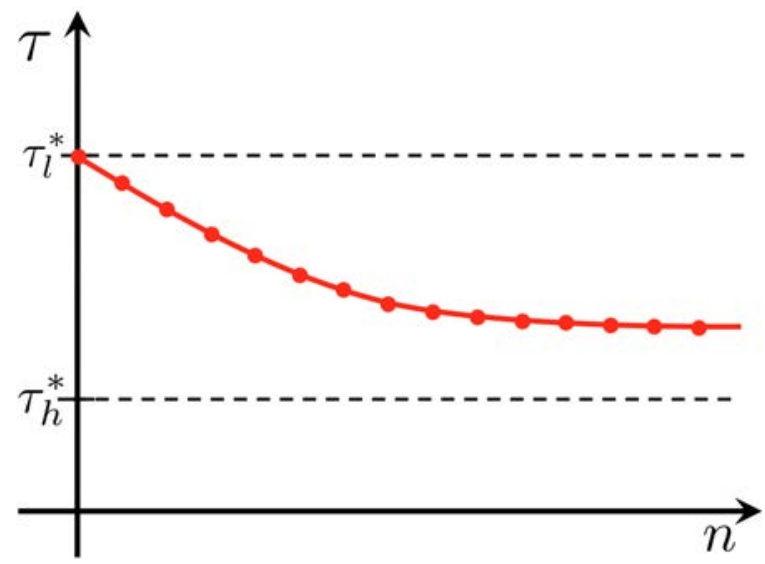

(a) $\gamma$ is small.

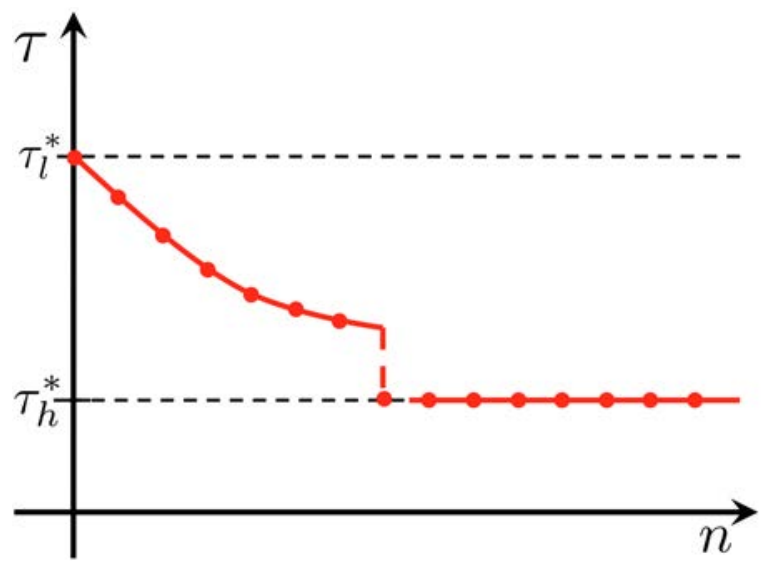

(b) $\gamma$ is large.

\section{Proposition 2.}

1. $\gamma^{*}(n)$ is decreasing in $n$. As $n \rightarrow \infty, \gamma^{*}(n) \rightarrow \kappa(\eta, \alpha)$, where $\kappa(\eta, \alpha) \in(0,1)$.

2. $\tau_{n}^{*}$ is decreasing in $n{ }^{18}$

There are two reasons that taxes decrease when $n$ increases. First, the tax rate in a somewhat representative equilibrium is $\left((2 n+1) \pi_{(n+1) L}^{L}\right)^{\frac{\alpha}{1-\alpha}} \tau_{l}^{*}$. This is decreasing in $n$, due to the fact that as $n$ increases, closer and closer to $50 \%$ of the districts are represented by high types. Thus, if $\gamma<\kappa(\eta, \alpha)$ then the tax rate be will continually decreasing as $n$ grows. On the other hand, if $\gamma>\kappa(\eta, \alpha)$ then at some $n$ the tax rate will drop from $\tau_{(n+1) L}^{*}>\tau_{h}^{*}$ to $\tau_{h}^{*}$ as the equilibrium moves from somewhat representative to representative ${ }^{19}$ As $n$ grows beyond this point, the tax rate will be $\tau_{h}^{*}$. Thus, the tax rate will either be smoothly decreasing in $n$, or will decrease smoothly in $n$ up until a point when the equilibrium switches from somewhat representative to unrepresentative, at which point there will be a sudden decrease in the tax rate.

\footnotetext{
${ }^{18}$ This is due, in part, to the way we have modeled the utility of government spending: the functional form implies spending is on local public goods. Thus, as districts become smaller, the effectiveness of this spending goes down - see, for example, the expression for $\tau_{l}^{*}$ in 2. Appendix B.5 shows the result still holds when using a slightly different citizen utility function that does not have this feature.

${ }^{19}$ When $\gamma$ and $\eta$ are particularly large, it may be the case that $\tau_{(n+1) L}^{*}<\tau_{h}^{*}$, as much of the tax revenue will go to the high-type legislator's district. Anticipating the outcome of the distributive stage, a majority composed of low-type legislators will set a relatively low tax rate in the tax-policy stage to prevent their districts from being expropriated. Similarly, it may be the case that $\tau_{(n+1) H}^{*}>\tau_{l}^{*}$. While these orderings are theoretically possible, they never obtain in equilibrium.
} 


\section{Theoretical Robustness}

The simplicity of our model starkly reveals the theoretical forces at work. However, some of our assumptions are clearly too restrictive, and may limit our results in important ways. Here we discuss three key assumptions: the perfect correlation between tax preferences and negotiating ability, that negotiating ability does not directly affect the setting of the tax rate, and the inability of legislators to commit to platforms other than their most preferred policies. Relaxing these assumptions does not qualitatively change our results.

\subsection{Imperfect Correlation between Types}

There are, of course, politicians who are successful in the private sector, but favor high taxes ${ }^{20}$ Allowing for a positive but imperfect correlation between tax preferences and legislative ability can be easily incorporated in our model as long as we maintain our assumption that the only signal of a candidate's type is his success. In this case, there is little effect on our results, and the existence of such a correlation may lower tax rates in equilibrium.

There are two ways in which tax preferences may be mismatched with type. A low-type candidate may actually favor low taxes, that is, have high-type tax preferences. This will make low-type candidates less appealing to low-type median voters, without changing the preferences of high-type voters (who already favor high-type candidates). Thus, taxes will be lower in equilibrium as low-type median voters will elect high types for lower values of $\gamma$, and even when they elect low-type legislators, these legislators may sometimes vote for low taxes.

The more subtle case is when success in the private sector is a perfect signal of a citizen's ability to direct resources to his district, but some high types may favor high taxes. We analyze this formally by assuming that with a small probability $q$ a high-type citizen will

\footnotetext{
${ }^{20}$ This is only one of four ways in which there may be an imperfect correlation between a legislator's preferences over tax rates and his negotiating ability. For each type, either negotiating ability or tax preferences may be mismatched with the candidate's type. If negotiating ability is mismatched with type, this will make low-type candidates more attractive (and high-type candidates less attractive) to low-type median voters. However, as indicated above, the more common concern is over mismatched tax preferences, perhaps because private-sector success is likely a more credible signal of ability than of preferences.
} 
vote for tax rates as if he had low income, $y_{l}$. This means that ability to direct funds to one's district and tax preferences are imperfectly correlated (with a positive correlation proportional to $1-q$ ). However, there is still a single signal of both dimensions of a citizen's type- his private sector success. This is a perfect signal of his negotiating ability, but, for high types, an imperfect signal of tax preferences.

\section{Proposition 3.}

1. $\gamma^{*}(q)$ is decreasing in $q$.

2. In unrepresentative equilibria, the average tax rate is increasing in $q$.

3. There exists a $\bar{q}>0$ such that for $q<\bar{q}$ expected taxes are lower in the unrepresentative equilibrium than in somewhat representative equilibria.

The first part of the proposition says that increasing $q$ widens the range of parameters for which the unrepresentative equilibrium is unique. Intuitively, the cost to a low-type median voter of electing a high type is reduced because the high type might share the low type's preferences for redistribution. The consequence of this, described in the second part of the proposition, is that values of $\gamma$ for which a somewhat representative equilibrium may exist would change to unrepresentative, with a corresponding increase in taxes, so long as $q$ is not too large. The third point says that the existence of high types with low-type tax preferences may raise the tax rate: when there are two or more high types with low-type tax preferences elected to the legislature, they will set the tax rate at $\tau_{l}^{*}$. However, as this happens somewhat rarely, the increase in the expected tax rate will be much smaller. Together, this suggests that the presence of high types with low-type tax preferences may actually raise tax rates relative to a model with perfect correlation in the dimensions of a citizen's type ${ }^{21}$

\subsection{Weighted Voting}

In our core model, the relative skill of legislators in apportioning funds is not reflected in the tax-setting stage. A potential way to mitigate this asymmetry is to assume that high-type

\footnotetext{
${ }^{21}$ Similarly, if a party has superior ability to screen candidates - that is, it can increase $q$ for its candidate pool - this may produce higher tax rates and less representative outcomes. For related findings on the role of parties, see Section 6.2 .2 .
} 
legislators have a higher voting weight in the tax-setting stage. This will not generally affect the results, and, when it does, will make the unrepresentative equilibrium hold whenever $\gamma>0$

This is easy to understand when there are only three districts $(n=1)$. Note that the only case in which the addition of voting weights can make a difference is when there are two low-type legislators and one high-type legislator, and the voting weight of the single high-type legislator is such that he can control the tax-setting process. In this case, there is no benefit to a low-type median voter of electing a low-type legislator, as he will not affect the tax rate, and will negotiate a lesser proportion of tax revenues for his district. As such, low-type median voters will always elect a high-type legislator when $\gamma>0$, and the resulting equilibrium will always be unrepresentative.

\subsection{Accountability and Commitment}

In the citizen-candidate framework, there is no scope for re-election incentives to influence politicians' actions in office (Barro, 1973; Ferejohn, 1986). As this framework is a building block of our theoretical construction we inherit this assumption. While this assumption is somewhat extreme, it makes our analysis transparent. If, instead, accountability was perfect and candidates could perfectly commit to a given tax policy, then, unsurprisingly, the policy outcome would be representative of the median voter's preferences.

There is little doubt that in reality political accountability is not perfect. It has been shown that factors such as term limits, inter- and intra-group conflict, and policy-making across multiple issue dimensions reduce accountability (Hatfield and Padró-i-Miquel, 2012, Herron and Shotts, 2006; Padró-i-Miquel, 2007; Padró i Miquel and Snowberg, 2012). Moreover, limited transparency in policy-making may reduce accountability (Holmstrom, 1979, Besley and Burgess, 2002).

While perfect accountability leads to fully representative outcomes, less than perfect accountability may lead to less representative outcomes. Explicitly micro-founding imperfect accountability would considerably complicate the analysis, and is beyond the scope of this 
paper. However, note that whenever accountability is imperfect, voters continue to face a trade-off when choosing legislators who are better at directing resources to their districts, but have policy preferences that are at odds with the voters on taxes or other dimensions. Imperfect accountability means that high-type politicians can take rents, and will do so by implementing lower tax rates whenever possible. Moreover, limited accountability may make outcomes worse, from the median voter's point of view, than no accountability. For example, one way to think about limited accountability is that high-type legislators once elected may follow the policy preferences of their low-type constituents. As shown in Section 4.1, this may actually make policy outcomes worse. Similarly, imperfect party discipline may also lower taxes in equilibrium, see Section 6.2.2.

\section{$5 \quad$ Empirical Regularities}

As noted in Section 1.2, there are many theories that seek to explain heterogeneity in the size of government. Our model contributes to this literature by reconciling the common pool mechanism with broad stylized facts about the size of government. We do so by adding a simple assumption - those who are more successful in the private sector are also better at negotiating resources for their district. This produces a theory that, we argue, allows us to organize stylized facts not just about the size of government, but also about who gets elected in democracies. In this section, we provide empirical support for our central assumption, and discuss additional stylized facts that our theory may help organize.

\subsection{Central Assumption}

Our results generally require only that voters believe our central assumption, not that it actually holds. This distinction is useful, as a direct test of the central assumption is infeasible since it involves assessing several variables that are often unmeasured, or unmeasurable. Instead, we ran a few simple surveys on convenience samples to assess voters' belief in our 
central assumption ${ }^{22}$ The questions on these surveys were aimed at ascertaining whether U.S. voters saw private sector success as a signal of distributive prowess, and furthermore, whether this perception was enough to overwhelm policy concerns in voting decisions.

We asked a sample of U.S. citizens $(n=1,076)$ to rank various professions in terms of the respondent's belief as to which would be most indicative of talent at "obtaining resources for your district (for example by obtaining funding for local projects)." Respondents ranked a list of professions from 1-6. These professions, with their average rank, were as follows: successful businessman (2.07), entrepreneur (2.38), successful lawyer (2.63), high school teacher (3.73), factory worker (4.73), and bus driver (5.46). We also asked the same respondents to rank people with different educational backgrounds in terms of their ability to secure funds for the voter's district. The rankings were: MBA (2.28), law degree (2.44), PhD (2.78), medical degree (3.83), university degree (4.16), and only high school degree (5.50).23 A clear pattern emerges in this data: more highly compensated professions, and educational backgrounds correlated with compensation, are perceived by voters as being indicative of the legislative skill of directing resources to a district.

We also asked a subset of this group $(n=233)$ a question aimed at understanding how they valued the trade-off between policy and directing resources to their district. They were asked to choose between a (hypothetical) congressional candidate that was "good at securing resources for your district: he has a long record of bringing in money for projects the district needs and prefers lower taxes, especially on high-income earners," and another that was "not very good at securing resources for your district and prefers higher taxes, especially on high-income earners." The first candidate was chosen by $73 \%$ of respondents. Self-identified Republicans chose the first candidate $93 \%$ of the time, versus $70 \%$ for selfidentified Democrats.

While this is supportive of the central assumption of our model, for it to have implications for policy, it must also be the case that the core assumption of the citizen-candidate

\footnotetext{
${ }^{22}$ We obtained our convenience samples in the U.S. through Amazon's Mechanical Turk. For more on the use of Mechanical Turk in survey research see Berinsky, Huber and Lenz (2012).

${ }^{23}$ All differences between rankings were significant at the $p<0.01$ level. The rankings of those who reported they voted in the last congressional election were not significantly different than those who did not.
} 
model holds as well. The analysis of roll-call votes is consistent with the hypothesis that wealthier legislators support lower taxes, and more generally, that legislators tend to support policies aligned with their private interests. In recent years, the literature has documented more and more examples supporting this assumption. In particular, Carnes (2013), shows that legislators from higher socio-economic status professions have more conservative voting records, even controlling for party. Additionally, Matter and Stutzer (2015) documents that state and national legislators who are attorneys are less likely to vote in favor of reforms restricting tort litigation, and more likely to vote for reforms that extend torts, than legislators from other professions.

Taken together, these results suggest that our central assumption is reasonable, and that it matches voter perceptions.

\subsection{Stylized Facts}

We use our results to organize stylized facts about taxes, redistribution, and representation. This organization is rough, due to the fact that our results, which rely on only two types and a simplified institutional structure, are quite stark.

The analysis of these stylized facts proceeds by noting that the ability to direct funds to one's district is important in the U.S. (high- $\gamma)$, but is relatively unimportant in most Western European countries (low- $\gamma$ ). Here we focus on three Western European countriesItaly, Germany, and the U.K.- due to the relative ease of obtaining descriptive data from them. However, the data in these countries is still imperfect, especially as it pertains to legislator wealth. A full comparative analysis is well beyond the scope of this theory paper.

When $\gamma>0$, then the rich will be over-represented in legislatures. The literature on legislative recruitment concludes, "[T]hat legislatures worldwide include more of the affluent than the less well-off, ... and more white-collar professionals than blue-collar workers" (Norris, 1997, p. 6). In all countries, distribution across districts should be relatively even. This is the most counter-intuitive (given our model) in high- $\gamma$ countries like the U.S. However, it agrees with the literature cited in Footnote 9. 
Other implications require us to compare high- and low- $\gamma$ countries. While the rich are over-represented in all countries, the over-representation should be particularly extreme in high- $\gamma$ countries. In countries such as Italy and Germany, about a quarter of legislators have no post-secondary education. Britain famously has coal-miner and factory-worker MPs. However, in the U.S., there are almost no legislators who are laborers or without college degrees (Carnes, 2013; Wessels, 1997). High- $\gamma$ countries should also be composed of higher productivity legislators. While this is difficult to compare in data, we note that members of the U.S. Congress introduce $\sim 5,000$ bills per year, while the Italian Parliament introduces $\sim 2,000$ bills a year, and the U.K. Parliament introduces substantially fewer.

Taxes should be lower in high- $\gamma$ countries, and, indeed, U.S. taxes at all levels of government are lower than in the U.K., Italy, or Germany.24

Finally, in high- $\gamma$ countries, low-type constituents should approve of the job done by their legislator, but disapprove of the broad policies enacted by the legislature. In the U.S., approval of individual congressmen and congresswomen is generally around 50\%, while approval of Congress itself is between $10-20 \% \cdot 25$

\section{Extensions}

The simplicity of our basic model makes it straight-forward to extend to other issues. Here we consider three: descriptive representation, party politics, and endogenously changing the institutional parameter $\gamma$. The first two cases allow us to organize a few more stylized facts with our model, while the third highlights interesting dynamics of institutional change. Additional extensions can be found in Appendix B.

\subsection{Descriptive Representation and Gender}

Our model makes predictions about descriptive representation - essentially, whether representatives have similar observable characteristics and preferences to their constituents. This

\footnotetext{
${ }^{24}$ See Footnote 1 and taxpolicycenter.org/briefing-book/how-do-us-taxes-compare-internationally

${ }^{25}$ See, for example, ropercenter.uconn.edu/data_access/tag/congressional_approval.html.
} 
has been largely overlooked by political economists in favor of examining ideological representation. However, representation of the voters themselves may be important when politician actions are difficult to monitor 26

Descriptive representation is not just ancillary to our model, but is the channel through which policy changes. Take, for example, proportional representation. In our model, this would be examined by setting $n=0$. In this case, redistribution between districts is no longer a force, and descriptive characteristics of legislators and policy are perfectly representative. This is in contrast to distributive channels emphasized in previous work (see, Persson and Tabellini, 2000, for a review).

While our model focuses on descriptive representation as it applies to class, it could also apply to any group with members perceived by society as being less able negotiators. A particularly interesting case is women, who are generally perceived as less capable negotiators Croson and Gneezy, 2009; Niederle and Vesterlund, 2008) or as having less bargaining power than men (Altonji and Black, 1999; Ayres and Siegelman, 1995; Harding, Rosenthal and Sirmans, 2003). Regardless of the correctness of these beliefs - and recent research indicates that they may be mistaken (Besley et al., 2014; Volden, Wiseman and Wittmer, 2013) our model makes the same predictions for the representation of men as it does for the rich because voters believe that representatives with either of these descriptive characteristics will be able to deliver more pork.

Some of our results can be directly extended to gender: men will be over-represented in all legislatures, and legislatures characterized by a focus on pork will have an even greater majority of men than those that are not. In April 2015, despite the fact that most countries are roughly 50\% women, only two countries in the world - Rwanda and Bolivia - had a lower house which is a majority women, and no country in the world has an upper house that is a majority women. Of the countries examined in Section 5, the U.S. had the lowest rate

\footnotetext{
${ }^{26} \mathrm{~A}$ concern for descriptive representation dates back to at least the Federalist Papers: "It is said to be necessary, that all classes of citizens should have some of their own numbers in the representative body, in order that their feelings and interests may be better understood and attended to." (Alexander Hamilton, The Federalist, no. 35.) For more recent normative arguments advocating descriptive representation see Birch (1972), Mansbridge (1999) and Pitkin (1967). For a more formal argument about the importance of elections in selecting types see Fearon (1999).
} 
of female representatives in the lower house (19.4\%), and Germany the highest (36.5\%). The U.S. ranks 73rd in the world, the U.K. 59th, Italy 33rd, and Germany 20th for female representation.

These two examples - class and gender - suggest our model can be used to examine claims made in the normative political philosophy literature. A common claim is that more legislative districts will lead to better descriptive representation. ${ }^{27}$ Paradoxically, in our model, more representatives lead to less representative equilibria: the share of the legislature that is rich (or male) increases with $n 28$

Another common conjecture is that stronger parties will improve descriptive representation (Committee on Political Parties, 1950; Hazan and Rahat, 2010). We examine this claim in the next subsection, which adds parties to our model. In particular, we find that allowing policy-motivated parties to control representation or discipline legislators has little effect on, and may even harm, descriptive representation. On the other hand, if parties can reduce competition between legislators for district-specific public goods, this can improve representation.

\subsection{Party Politics}

This section adds parties to our theory, and gives them increasing roles in candidate selection and policy formation. We first examine purely policy-motivated parties who can nominate candidates according to a closed list. We then give them the ability to constrain their legislators' tax policies. Parties have little effect on our results, and, in some cases, may worsen the issues identified above.

\footnotetext{
${ }^{27}$ For example, Dahl and Tufte $(1973)$ argues that larger legislatures should promote representation of minorities, and Taagepera and Shugart (1989) suggests that states with small legislatures (in particular smaller than the cube root of their population size) cannot achieve representational goals. Furthermore, the National Conference of State Legislatures argues that smaller legislative districts are preferable as, "The legislature is designed to provide a cross-section of all points of view." (ncsl.org/research/about-statelegislatures/sizes-of-legislatures.aspx).

${ }^{2}$ This is a direct corollary of Proposition 2 .
} 


\subsubsection{Party Control of Candidate Nominations}

We begin by adding two policy-motivated parties that simultaneously nominate a slate $2 n+1$ citizen candidates, one for each legislative district:29 These slates are announced before the election stage (see Section 2.2). That is, there is a closed list.

The two parties are $L$ - the party of low types, which has a preference for high tax ratesand $H$ - the party of high types, which has a preference for low tax rates. If the tax rate chosen by the legislature is $\tau^{*}$, then the utility of the two parties is:

$$
U_{L}=f_{L}\left(\left|\tau^{*}-\tau_{l}\right|\right) \quad U_{H}=f_{H}\left(\left|\tau^{*}-\tau_{h}\right|\right)
$$

we assume each $f_{j}$ is strictly decreasing, so is maximized when $\tau^{*}=\tau_{j}^{*}$.

\section{Proposition 4.}

1. If $0<\gamma<\gamma^{*}(n)<1$ then party $L$ nominates at least $n+1$ low-type candidates in districts with low-type median voters, and is otherwise indifferent. Party $H$ nominates $n$ high-type candidates, and is otherwise indifferent.

2. If $\gamma^{*}(n)<\gamma<1$ then party $H$ nominates high-type candidates in every district. Party $L$ is indifferent in all districts.

3. All patterns of representation and taxation continue to hold as in Proposition 1 .

The patterns of nomination may seem somewhat odd. However, if we eliminate weakly dominated strategies, then each party would only nominate citizens of its type. This leads to exactly the same slate of candidates assumed in the setup for Proposition 1, and thus the patterns there will trivially hold. The intuition behind these nomination patterns is that although the low-type party can supply low-type candidates in each district, this will not change the type for whom voters want to vote. If the median voter of a district wants to elect a high type, then the high-type party is more than happy to supply one as a candidate. As such, the introduction of parties with perfect control over nomination does not affect our results 30

\footnotetext{
${ }^{29}$ If parties value winning even very slightly, then Downsian logic holds, and both parties will want to nominate whoever voters want to elect. As such, the equilibrium patterns in Proposition 1 hold trivially.

${ }^{30}$ There is one difference in the logic between this proposition and Proposition 1 . when $\gamma<\gamma^{*}(n)$ the reason the unrepresentative equilibrium is not stage strong is slightly different. To support the unrepresentative
} 


\subsubsection{Party Discipline}

Suppose, in addition to closed-list nominations, parties could somehow discipline their legislators to adopt tax rates other than those most preferred by the legislators. We model (imperfect) party discipline by assuming a party can promise voters that their politicians, if elected, will vote for a tax rate that is (at most) $\Delta_{\tau}$ away from the legislator's ideal tax rate.

Parties' ability to imperfectly discipline legislators will never increase representation. However, in two circumstances it can increase the tax rate. The first is when the equilibrium is unrepresentative. In this case, high-type candidates from the party $L$ can be forced to implement a higher tax rate. Second, if $\Delta_{\tau}$ is large enough then any equilibrium will approximate a representative equilibrium - that is $\Delta_{\tau} \approx \tau_{l}^{*}-\tau_{h}^{*}$.

In between these circumstances are values of $\Delta_{\tau}$ for which the ability of parties to discipline their legislators leads to lower tax rates and less representative equilibria.

Proposition 5. If $0<\gamma<\gamma^{*}(n)$, then there exists some $\Delta_{\tau}^{*}$ such that when $\Delta_{\tau} \in$ $\left(\Delta_{\tau}^{*}, \tau_{(n+1) L}^{*}-\tau_{h}^{*}\right)$ then the tax rate and representation will be lower in equilibrium when parties can discipline their legislators than when they cannot.

To understand this result, note that when $0<\gamma<\gamma^{*}(n)$ all stage-strong equilibria are somewhat unrepresentative. Then, consider the lower bound of $\Delta_{\tau}$ in the proposition. At this level, it will be the high-type party — not the low-type party - that will take advantage of the ability to discipline its politicians. Specifically, it will promise that high types elected under its banner will implement a tax rate $\tau_{h}^{*}+\Delta_{\tau}^{*}$, which will be sufficient to change the equilibria from somewhat representative to unrepresentative, thus reducing representation. Correspondingly the tax rate will decrease from from $\tau_{(n+1) L}^{*}$ to $\tau_{h}^{*}+\Delta_{\tau}^{*}<\tau_{(n+1) L}^{*}$. The low-type party will need to respond by also nominating high types and promising a tax rate

equilibrium, both parties must nominate high types in all districts. For this to be the case, the low-type party must believe that if it nominates low types in districts with low-type median voters, then all districts would still elect high types. As this is a subgame-perfect equilibrium of the continuation subgame, it is an equilibrium. However, this continuation play is not stage strong: in particular, if the low-type party nominated low types, a deviation in the election stage by $n+1$ districts with low-type median voters would make them both strictly better off. As such, the unrepresentative equilibrium is not stage strong when (4) holds. 
of $\tau_{h}^{*}+\Delta_{\tau}^{*}$-if it failed to do so then the high party would promise a lower tax rate and win, making the low-type party strictly worse off 31

Thus, parties with limited ability to discipline politicians may lead to less representative outcomes than parties with no such ability.

\subsubsection{Limiting Competition for Funds}

If parties could change the level of $\gamma$, this would have a profound impact on our theoretical findings. But how can this actually be achieved? From Section 6.2.1, it should be clear that even if a party could limit competition, it may not want to, as a relatively even distribution of funds may cause a loss of seats that some targeting of funds would help secure.

An example of how $\gamma$ might actually be lowered comes from Great Britain. In the British parliament, the ability to channel funds to one's district is severely curtailed. All bills on serious matters such as budgeting must be sponsored by the government (Prime Minister and his or her cabinet). Each year only 20 bills may be sponsored by individual members, so called private bills. These bills are often quite limited in scope: for example, they may seek to keep a hospital or local community center open despite bureaucratic cuts.

More generally, the results discussed above make predictions about the importance of parties to policy outcomes. Specifically, there will be very little difference between parties' implemented policies in high- $\gamma$ countries. In the U.S., a change in the party of the President moves the U.S. stock market by $\sim 2 \%$, and a change in the party controlling Congress moves the stock market by $\sim 0.2 \%$ (Snowberg, Wolfers and Zitzewitz, 2007a $b$ ). In contrast, in the U.K., a change in the government moves the British stock market by $\sim 11 \%$ (Herron, 2000). Moreover, in high- $\gamma$ countries, the distribution of spending across districts should be independent of the political party of a district's legislator. This appears to be the case (Boone, Dube and Kaplan, 2014).

\footnotetext{
${ }^{31} \mathrm{~A}$ similar logic applies if parties are able to promise a specific value of $\gamma$ as long as the low-type party cannot promise $\gamma=0$. In Section 6.3, we consider how changing institutions $(\gamma)$ affect the long-run play of the game.
} 


\subsection{Changing Institutions}

Our final extension examines a dynamic approach to the endogenous determination of $\gamma$. We show that the specifics of institutional change, particularly whether it is slow or fast, are critically important for whether a low level of $\gamma$ can be achieved and maintained. Technical details of the discussion that follows, as well as specific results, can be found in Appendix B.1.

Under our definition of slow institutional change, $\gamma$ in the current period is set by the legislature in the previous period. Under fast institutional change, the current legislature is free to set $\gamma$ before any policy decisions are made ${ }^{32}$ When institutional change is slow, the unrepresentative equilibrium will be an absorbing state, whereas the representative or somewhat representative equilibria will not be. That is, the repeated game will eventually get "stuck" in the unrepresentative equilibrium. On the other hand, if institutional change is fast, then the equilibrium in each period will be representative. The asymmetry in "stickiness" of the two types of equilibria, along with the fact that there are no costs to institutional change in our model, present a rare example where fast may be preferable to slow institutional change.

Under slow institutional change, if high types are ever able to set $\gamma=1$, low types will face a trade-off in trying to set $\gamma=0$. Electing low types in the current period results in a current period loss because low-type legislators will be expropriated by high-type legislators. On the other hand, with enough low-type legislators, $\gamma=0$ will hold in the next period. For ranges of parameter values, the cost of expropriation will be too high, and low-type median voters prefer to elect high types in the current period. High-type legislators will perpetuate the $\gamma=1$ status quo, thus, outcomes will be unrepresentative from then on. The path of tax rates in this sequence of events, as well as under fast institutional change, is displayed in Figure 3 .

Alternatively, if the current legislature is able to set its own institutional rules, then a low-type median voter will face no conflict between the current period and future periods.

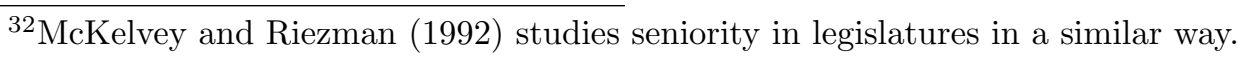


Figure 3: Progression of tax rates over time when $\delta<\delta^{*}(p)$.

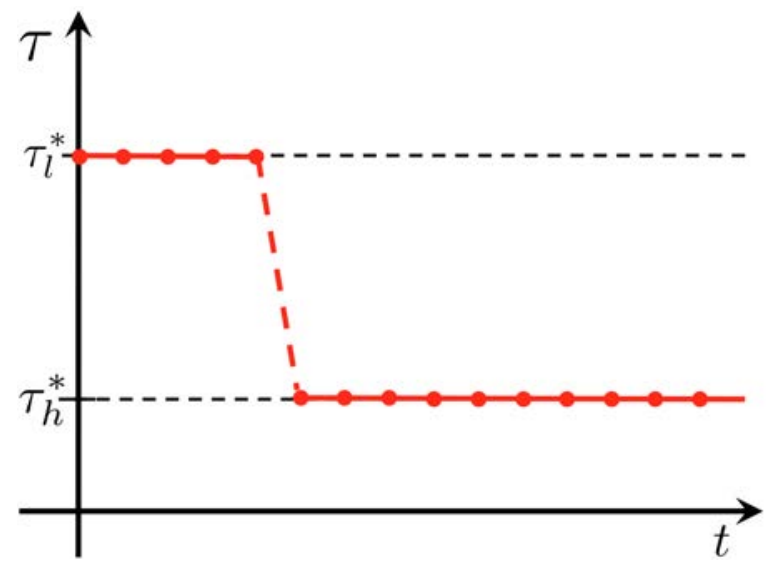

(a) Slow institutional change leads to permanently unrepresentative equilibria.

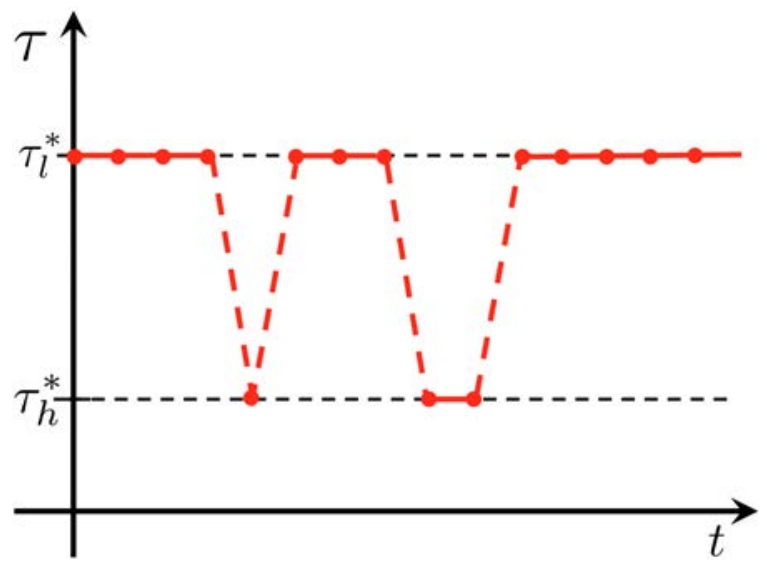

(b) Fast institutional change allows for representative equilibria.

In particular, if the majority of the legislature is composed of low types, then they will vote to set $\gamma=0$ in the current period, tax revenues will be equally apportioned, and the tax rate set by the legislature will be the ideal tax rate of a low type. Moreover, $\gamma=1$ will only occur when there are at least $n+1$ high-type median voters, and thus, even these periods feature representative equilibria.

Other factors that might slow institutional change will only make this problem worse: if it takes more periods for an institutional change to occur, or there are super-majority requirements for institutional change, this will only make the unrepresentative equilibrium stickier. Additionally, myopic voters, who act as though their discount rate were 0, would be unable to make the tradeoff needed to change the state to $\gamma=0$.

This last point suggests that institutions which take decisions over $\gamma$ out of the hands of the legislature may be preferred. In particular, if there were a country-wide constitutional referendum, low-type voters could coordinate to set $\gamma=0$, resulting in representative equilibria in every period. This further suggests that electing an executive by nation-wide popular vote may serve as a check on the coordination problems caused by local representation. While examining executive-legislative interactions is beyond the scope of this paper, it is one of many possible directions for future research, a few of which are discussed in the next section. 


\section{Discussion: Accountability and Representation}

This paper studies redistribution both between the rich and the poor and between legislative districts. We augment workhorse political economy models with the simple assumption that those who are more successful in the private sector will tend to be more successful at negotiating resources for their districts when elected to the legislature. This leads to a few, stark, results: First, the rich will always be over-represented in legislatures. Second, this will reduce taxes below the rate preferred by the median voter of the median district. Third, when the ability to direct resources to one's district is important, then all districts will elect rich legislators, and the tax rate will be the most preferred tax rate of the rich.

These results are robust to, and, indeed, exacerbated by, many traditional remedies for political agency problems. First, larger legislatures are more likely to be unrepresentative: that is, more representation may actually make government less representative. Second, policy-motivated parties that can discipline legislators may lead to less representation and lower taxes. Third, fast institutional change allows for representative equilibria, while slower institutional change makes unrepresentative equilibria "sticky": once an unrepresentative equilibrium occurs, the legislature will stay in that state forever.

An attractive feature of our model is that it makes predictions about descriptive representation, an area not usually addressed in the political economy literature. We believe that a renewed focus on descriptive representation would be useful. In particular, theories of descriptive representation would lend themselves to cleaner, more direct tests than theories of ideological representation. This is due to the fact that, despite many methodological advances, measuring and comparing legislator ideologies is especially difficult because legislative voting is endogenous, and the theories that we seek to test often make identification of ideologies impossible (Achen, 1977, 1978; Clinton, 2007; Lewis and Tausanovitch, 2013). On the other hand, testing theories of descriptive representation requires only compiling statistics on the demographics of legislators. While such data is currently surprisingly difficult to obtain, this seems to be, in part, due to the fact that such data has little use without the 
predictions of positive theories to test ${ }^{33}$

Our results document numerous difficulties in trying to establish more representative political outcomes. However, it is important to note that behavioral factors exhibited by voters, such as imperfect recall, or a reliance on their own experiences to make political choices Ansolabehere, Meredith and Snowberg, 2014, Healy, Persson and Snowberg, 2017; Ortoleva and Snowberg, 2015) may further reduce electoral accountability. This is of particular importance when we consider more complex tax instruments, like differential taxes on income from labor and capital. As the rich are more likely to hold capital, our model would imply that taxes will tend to be tilted away from capital income and toward labor income. Moreover, as those without capital income are less likely to be aware of discrepancies between labor and capital income taxation, this provides a further incentive to tilt taxation in this way ${ }^{34}$ This can make policies aimed at reducing the rate of capital accumulation and inequality especially difficult to implement (Piketty, 2014) ${ }^{35}$

More generally, this work demonstrates a previously unappreciated downside to local representation in legislatures: it advantages groups that are perceived as better at negotiating resources for their district, and these groups will take rents according to their preferences.

\footnotetext{
${ }^{33}$ For recent advances in particular countries, see Galasso et al. (2010) and Dal Bo et al. (2017).

${ }^{34}$ On the other hand, if voters are aware of these dimensions, this would lead to different results. In particular, the awareness of difficult-to-observe policy instruments increases the importance of electing someone with preferences similar to yours. This would push voters to focus on "character" over other features of a candidate, such as competence.

${ }^{35}$ Under the U.S. tax code, hedge fund managers are allowed to represent their labor income as capital income, subject to a much lower rate of taxation, and there are three different ways for individuals to make expenditures on private jets tax deductible (Kristof, 2014).
} 


\section{References}

Achen, Christopher H. 1977. "Measuring Representation: Perils of the Correlation Coefficient." American Journal of Political Science 21(4):805-815.

Achen, Christopher H. 1978. "Measuring representation." American Journal of Political Science 22(3):475-510.

Altonji, Ian and Rebecca Black. 1999. Race and Gender in the Labor Market. In Handbook of Labor Economics, ed. Orin Ashenfelter and David Card. Amsterdam: Elsevier pp. 31433251.

Ansolabehere, Stephen, Marc Meredith and Erik Snowberg. 2014. "Mecro-Economic Voting: Local Information and Micro-Perceptions of the Macro-Economy." Economics \& Politics forthcoming.

Ayres, Ian and Peter Siegelman. 1995. "Race and Gender Discrimination in Bargaining for a New Car." American Economic Review 85(3):304-321.

Baron, David P. and John A. Ferejohn. 1989. "Bargaining in Legislatures." The American Political Science Review 83(4):1181-1206.

Barro, Robert J. 1973. "The Control of Politicians: An Economic Model." Public Choice 14(1):19-42.

Bartels, Larry M. 2007. Unequal Democracy: The Political Economy of the New Gilded Age. Princeton, New Jersey: Princeton University Press.

Berinsky, Adam J, Gregory A Huber and Gabriel S Lenz. 2012. "Evaluating Online Labor Markets for Experimental Research: Amazon.com's Mechanical Turk." Political Analysis $20(3): 351-368$.

Bernheim, B Douglas, Bezalel Peleg and Michael D Whinston. 1987. "Coalition-proof Nash Equilibria: I. Concepts." Journal of Economic Theory 42(1):1-12.

Bernheim, B Douglas and Michael D Whinston. 1987. "Coalition-proof Nash Equilibria: II. Applications." Journal of Economic Theory 42(1):13-29.

Berry, Christopher R. and Anthony Fowler. 2016. "Cardinals or Clerics? Congressional Committees and the Distribution of Pork." American Journal of Political Science 60(3):692708.

Berry, Christopher R. Barry C. Burden and William G. Howell. 2010. "The President and the Distribution of Federal Spending." American Political Science Review 104(4):783-799.

Besley, Timothy. 2007. Principled Agents?: The Political Economy of Good Government. Oxford University Press.

Besley, Timothy, Olle Folke, Torsten Persson and Johanna Rickne. 2014. "Gender Quotas and the Crisis of the Mediocre Man: Theory and Evidence from Sweden." Mimeo. 
Besley, Timothy and Robin Burgess. 2002. "The Political Economy of Government Responsiveness: Theory and Evidence from India." The Quarterly Journal of Economics $117: 1415-1451$.

Besley, Timothy and Stephen Coate. 1997. "An Economic Model of Representative Democracy." Quarterly Journal of Economics 112(1):85-114.

Birch, Anthony H. 1972. Representation. London, UK: Macmillan.

Boone, Christopher, Arindrajit Dube and Ethan Kaplan. 2014. "The Political Economy of Discretionary Spending: Evidence from the American Recovery and Reinvestment Act." Brookings Papers on Economic Activity .

Campante, Felipe R. 2011. "Redistribution in a Model of Voting and Campaign Contributions." Journal of Public Economics 95(7-8):646-656.

Carnes, Nicholas. 2013. White-Collar Government: The Hidden Role of Class in Economic Policy Making. Chicago, IL: University of Chicago Press.

Caselli, Francesco and Massimo Morelli. 2004. "Bad Politicians." Journal of Public Economics 88(3):759-782.

Chari, Varadarajan V, Larry E Jones and Ramon Marimon. 1997. "The Economics of SplitTicket Voting in Representative Democracies." The American Economic Review 87(5):957976.

Chen, Jowei and Jonathan Rodden. 2013. "Unintentional Gerrymandering: Political Geography and Electoral Bias in Legislatures." Quarterly Journal of Political Science 8(3):239269.

Christiansen, Nels. 2013. "Strategic Delegation in a Legislative Bargaining Model with Pork and Public Goods." Journal of Public Economics 97:217-229.

Clinton, Joshua D. 2007. "Lawmaking and Roll Calls." Journal of Politics 69(2):457-469.

Committee on Political Parties. 1950. "Toward a More Responsible Two-Party System." Special issue of the American Political Science Review.

Croson, Rachel and Uri Gneezy. 2009. "Gender Differences in Preferences." Journal of Economic Literature 47(2):448-474.

Dahl, Robert A. and Edward R. Tufte. 1973. Size and Democracy. Stanford, California: Stanford University Press.

Dal Bo, Ernesto, Frederico Finan, Olle Folke, Torsten Persson and Johanna Rickne. 2017. "Who Becomes A Politician?" Quarterly Journal of Economics 132:1877-1914.

Downs, Anthony. 1957. An Economic Theory of Democracy. New York, NY: Harper Collins. 
Dynes, Adam M. and Gregory A. Huber. 2015. "Partisanship and the Allocation of Federal Spending: Do Same-Party Legislators or Voters Benefit from Shared Party Affiliation with the President and House Majority?" American Political Science Review 109(1):172-186.

Eraslan, Hülya. 2002. "Uniqueness of Stationary Equilibrium Payoffs in the Baron-Ferejohn Model." Journal of Economic Theory 103(1):11-30.

Fearon, James D. 1999. Electoral Accountability and the Control of Politicians: Selecting Good Types versus Sanctioning Poor Performance. In Democracy, Accountability, and Representation, ed. Adam Przeworski, Bernard Manin and Susan C. Stokes. Cambridge University Press pp. 55-97.

Ferejohn, John. 1986. "Incumbent Performance and Electoral Control." Public Choice $50(1): 5-25$.

Fernández, Raquel and Gilat Levy. 2008. "Diversity and Redistribution." Journal of Public Economics 92:925 - 943.

Frank, Thomas. 2004. What's the Matter with Kansas? How Conservatives Won the Heart of America. New York: Henry Holt and Co.

Gagliarducci, Stefano and Tommaso Nannicini. 2013. "Do Better Paid Politicians Perform Better? Disentangling Incentives from Selection." Journal of the European Economic Association 11(2):369-398.

Galasso, Vincenzo, Massimiliano Landi, Andrea Mattozzi and Antonio Merlo. 2010. The Labor Market of Italian Politicians. In The Ruling Class: Management and Politics in Modern Italy, ed. Tito Boeri, Antonio Merlo and Andrea Prat. Oxford University Press pp. $7-104$.

Gilens, Martin and Benjamin I. Page. 2014. "Testing Theories of American Politics: Elites, Interest Groups, and Average Citizens." Perspectives on Politics forthcoming.

Groseclose, Tim. 2001. "A Model of Candidate Location when one Candidate has a Valence Advantage." American Journal of Political Science 45(4):862-886.

Harding, John P., Stuart S. Rosenthal and C. F. Sirmans. 2003. "Estimating Bargaining Power in the Market for Existing Homes." Review of Economics and Statistics 85(1):178188.

Harstad, Bard. 2010. "Strategic Delegation and Voting Rules." Journal of Public Economics 94:102-113.

Hatfield, John William and Gerard Padró-i-Miquel. 2012. "A Political Economy Theory of Partial Decentralization." Journal of the European Economic Association 10(3):605-633.

Hazan, Reuven Y. and Gideon Rahat. 2010. Democracy within Parties: Candidate Selection Methods and Their Political Consequences. Oxford, UK: Oxford University Press. 
Healy, Andrew, Mikael Persson and Erik Snowberg. 2017. "Digging into the Pocketbook: Evidence on Economic Voting from Income Registry Data Matched to a Voter Survey." American Political Science Review 111(4):771-785.

Herron, Michael C. 2000. "Estimating the Economic Impact of Political Party Competition in the 1992 British Election." American Journal of Political Science 44(2):326-337.

Herron, Michael C. and Kenneth W. Shotts. 2006. "Term Limits and Pork." Legislative Studies Quarterly 31(3):383-403.

Hix, Simon and Abdul Noury. 2016. "Government-Opposition or Left-Right? The Institutional Determinants of Voting in Legislatures." Political Science Research and Methods $4: 249-273$.

Holmstrom, Bengt. 1979. "Moral Hazard and Observability." Bell Journal of Economics $10: 74-91$.

Hotelling, Harold. 1929. "Stability in Competition." The Economic Journal 39(153):41-57.

Huber, John D and Michael M Ting. 2013. "Redistribution, Pork, and Elections." Journal of the European Economic Association 11(6):1382-1403.

Kristof, Nicholas. 2014. "A Nation of Takers?" The New York Times p. A31.

Lewis, Jeffrey B. and Chris Tausanovitch. 2013. "Has Joint Scaling Solved the Achen Objection to Miller and Stokes?" UCLA, mimeo.

Mansbridge, Jane. 1999. "Should Blacks Represent Blacks and Women Represent Women? A Contingent "Yes"." The Journal of Politics 61(3):628-657.

Mansbridge, Jane. 2009. "A Selection Model of Political Representation." Journal of Political Philosophy 17(4):369-398.

Matter, Ulrich and Alois Stutzer. 2015. "The Role of Lawyer-Legislators in Shaping the Law: Evidence from Voting on Tort Reforms." Journal of Law and Economics 58(2):357-384.

Mattozzi, Andrea and Antonio Merlo. 2008. "Political Careers or Career Politicians?" Journal of Public Economics 92(3):597-608.

McKelvey, Richard D and Raymond Riezman. 1992. "Seniority in Legislatures." American Political Science Review 86(4):951-965.

Meltzer, Allan H. and Scott F. Richard. 1981. "A Rational Theory of the Size of Government." The Journal of Political Economy 89(5):914-927.

Messner, Matthias and Mattias K Polborn. 2004. "Paying Politicians." Journal of Public Economics 88(12):2423-2445.

Miller, Warren E and Donald E Stokes. 1963. "Constituency Influence in Congress." American Political Science Review 57(1):45-56. 
Niederle, Muriel and Lise Vesterlund. 2008. "Gender Differences in Competition." Negotiation Journal 24(4):447-463.

Norris, Pippa. 1997. Theories of Recruitment. In Passages to Power: Legislative Recruitment in Advanced Democracies, ed. Pippa Norris. Cambridge, UK: Cambridge University Press chapter 1, pp. 1-14.

Ortoleva, Pietro and Erik Snowberg. 2015. "Overconfidence in Political Behavior." American Economic Review 105(2):504-535.

Osborne, Martin J. and Al Slivinski. 1996. "A Model of Political Competition with CitizenCandidates." The Quarterly Journal of Economics 111(1):65-96.

Padró-i-Miquel, Gerard. 2007. "The Control of Politicians in Divided Societies: The Politics of Fear." Review of Economic Studies 74(4):1259-1274.

Padró i Miquel, Gerard and Erik Snowberg. 2012. "The Lesser Evil: Executive Accountability with Partisan Supporters." Journal of Theoretical Politics 24(1):19-45.

Persson, Torsten, Gerard Roland and Guido Tabellini. 1997. "Separation of Powers and Political Accountability." The Quarterly Journal of Economics 112(4):1163-1202.

Persson, Torsten and Guido Tabellini. 2000. Political Economics: Explaining Economic Policy. Cambridge, Massachusetts: MIT Press.

Pettersson-Lidbom, Per. 2012. "Does the Size of the Legislature Affect the Size of Government? Evidence from Two Natural Experiments." Journal of Public Economics 96(3):269278.

Piketty, Thomas. 2014. Capital in the 21st Century. Cambridge, MA: Harvard University Press.

Pitkin, Hanah. 1967. The Concept of Representation. Berkeley, CA: University of California Press.

Primo, David M and James M Snyder. 2008. "Distributive Politics and the Law of 1/n." The Journal of Politics 70(02):477-486.

Snowberg, Erik, Justin Wolfers and Eric Zitzewitz. $2007 a$. "Partisan Impacts on the Economy: Evidence from Prediction Markets and Close Elections." The Quarterly Journal of Economics 122(2):807-829.

Snowberg, Erik, Justin Wolfers and Eric Zitzewitz. 2007b. "Party Influence in Congress and the Economy." Quarterly Journal of Political Science 2(3):277-286.

Stokes, Donald E. 1963. "Spatial Models of Party Competition." The American Political Science Review 57(2):368-377.

Taagepera, Rein and Matthew S. Shugart. 1989. Seats and Votes: The Effects and Determinants of Electoral Systems. New Haven, Connecticut: Yale University Press. 
Tullock, Gordon. 1959. "Problems of Majority Voting." The Journal of Political Economy 67(6):571-579.

Volden, Craig and Alan E Wiseman. 2014. Legislative Effectiveness in the United States Congress: The Lawmakers. Cambridge University Press.

Volden, Craig, Alan E Wiseman and Dana E Wittmer. 2013. "When Are Women More Effective Lawmakers Than Men?" American Journal of Political Science 57(2):326-341.

Volden, Craig and Alan Wiseman. 2007. "Bargainig in Legislatures over Particularistic and Collective Goods." American Political Science Review 101:79 - 92.

Weingast, Barry R. 1979. "A Rational Choice Perspective on Congressional Norms." American Journal of Political Science pp. 245-262.

Weingast, Barry R. 1994. "Reflections on Distributive Politics and Universalism." Political Research Quarterly pp. 319-327.

Weingast, Barry R., Kenneth A. Shepsle and Christopher Johnsen. 1981. "The Political Economy of Benefits and Costs: A Neoclassical Approach to Distributive Politics." The Journal of Political Economy 89(4):642-664.

Wessels, Bernhard. 1997. Germany. In Passages to Power: Legislative Recruitment in Advanced Democracies, ed. Pippa Norris. Cambridge, UK: Cambridge University Press pp. $76-97$. 


\section{A Proofs-Not Intended for Publication}

\section{Proposition 1.}

1. If $\gamma=0$, then every equilibrium is representative with tax rate $\tau_{l}^{*}$, and all districts receive an equal proportion of the tax revenues.

2. If $0<\gamma<\gamma^{*}(n)<1$ there are two types of equilibria:

(a) Unrepresentative equilibria, with the legislature composed of all high types, and tax rate $\tau_{h}^{*}$. These equilibria are not stage strong.

(b) Somewhat representative, with the legislature composed of $n+1$ low types and $n$ high types, and tax rate $\left[(2 n+1) \pi_{(n+1) L}^{L}\right]^{\frac{\alpha}{1-\alpha}} \tau_{l}^{*}<\tau_{l}^{*}$.

3. If $\gamma^{*}(n)<\gamma<1$ then the unique equilibrium is unrepresentative with tax rate $\tau_{h}^{*}$, and all districts receive an equal proportion of the tax revenues.

If $\frac{z}{2 n+1}>\frac{1}{\gamma(\eta-1)}\left(\eta^{\frac{1}{\alpha}}\left(\frac{1-\alpha}{\eta-\alpha}\right)^{\frac{1-\alpha}{\alpha}}-1\right)$ this equilibrium is stage strong.

Proof of Proposition 1: Define $\pi_{r k}^{k^{\prime}}$ as the share of tax revenues returned to a district by a legislator of type $k^{\prime} \in\{L, H\}$ when the majority is composed of $r \geq n+1$ legislators of type $k \in\{L, H\}$. Using this notation, and taking first order conditions yields that the tax rate set by the legislature will be: $\tau_{r L}^{*}=\left((2 n+1) \pi_{r L}^{L}\right)^{\frac{\alpha}{1-\alpha}} \tau_{l}^{*}$ when the majority of the legislature is low types, and $\tau_{r H}^{*}=\left((2 n+1) \pi_{r H}^{H}\right)^{\frac{\alpha}{1-\alpha}} \tau_{h}^{*}$ when the majority of the legislature are high types, where $\tau_{l}^{*}$ and $\tau_{h}^{*}$ are the tax rates set by the legislature when it is composed entirely of low types or high types respectively, as defined in (2).

In what follows we will use the notation $u_{h}(k \mid(2 n+1-(j+1)) L, j H)$ to denote the utility of a high-type median voter of electing a legislator of type $k \in\{L, H\}$ when there are $j$ high-type legislators that have been elected to the legislature $\left(u_{l}(k \mid(2 n+1-(j+1)) L, j H)\right.$ in the case of a low-type median voter).

Consider the incentives of a voter when the majority of the legislature is low types, and there are $j<n$ high types that have been elected to the legislature. First, notice that if a low-type median voter wants to elect a high-type legislator, a fortiori a high-type median voter wants to elect a high-type legislator. Second, if a low-type median voter wants to elect a high-type legislator when there are $j<n$ high-type legislators that have been elected in the legislature, a fortiori a low-type median voter wants to elect a high-type legislator when 
there are $j-1$ high-type legislators that have been elected. Indeed, from the perspective of a low-type median voter, the fewer the high-types in the legislature, the higher the benefit of electing a high-type in the distributive stage and the lower the cost of electing a high-type in the tax-setting stage.

The utility that a low-type median voter will get when there are $j=n-1$ high-type legislators that have been elected to the legislature, and she electes a high-type legislator is:

$$
\begin{aligned}
& u_{l}(H \mid(n+1) L,(n-1) H)=(1\left.-\left((2 n+1) \pi_{(n+1) L}^{L}\right)^{\frac{\alpha}{1-\alpha}} \tau_{l}^{*}\right) y_{l} \\
&+\frac{1}{\alpha}\left(\pi_{(n+1) L}^{H}\left((2 n+1) \pi_{(n+1) L}^{L}\right)^{\frac{\alpha}{1-\alpha}} \bar{y} \tau_{l}^{*}\right)^{\alpha} \\
&=y_{l}+\left(\frac{\bar{y}}{y_{l}}\right)^{\frac{\alpha}{1-\alpha}} \frac{\left(\pi_{(n+1) L}^{L}\right)^{\frac{\alpha}{1-\alpha}}}{\alpha}\left(\left(\frac{\pi_{(n+1) L}^{H}}{\pi_{(n+1) L}^{L}}\right)^{\alpha}-\alpha\right)
\end{aligned}
$$

and, correspondingly, the utility that a low-type median voter will get when electing a lowtype legislator is

$$
u_{l}(L \mid(n+1) L,(n-1) H)=y_{l}+\left(\frac{\bar{y}}{y_{l}}\right)^{\frac{\alpha}{1-\alpha}} \frac{\left(\pi_{(n+2) L}^{L}\right)^{\frac{\alpha}{1-\alpha}}}{\alpha}(1-\alpha) .
$$

Hence, a low-type will want to elect a high-type if and only if

$$
\left(\frac{\pi_{(n+1) L}^{H}}{\pi_{(n+1) L}^{L}}\right)^{\alpha}-\alpha>(1-\alpha)\left(\frac{\pi_{(n+2) L}^{L}}{\pi_{(n+1) L}^{L}}\right)^{\frac{\alpha}{1-\alpha}}
$$

After substituting the expression for the $\pi \mathrm{s}$ and simplifying, we get that a low-type will want to elect a high-type when low-types are in the majority (and doing so will not change the majority) if and only if

$$
(1-\gamma+\gamma \eta)^{\alpha}-\alpha-(1-\alpha)\left(\frac{n(1-\gamma+\gamma \eta)+n+1}{(n-1)(1-\gamma+\gamma \eta)+n+2}\right)^{\frac{\alpha}{1-\alpha}}>0
$$

Notice that the left-hand-side of (7) is minimized when $n=1$, that is, when there are three 
districts and two of them are electing low types. Hence (7) will hold whenever

$$
(1-\gamma+\gamma \eta)^{\alpha}-\alpha-(1-\alpha)\left(\frac{(1-\gamma+\gamma \eta)+2}{3}\right)^{\frac{\alpha}{1-\alpha}}>0
$$

Notice that the left-hand-side of $(8)$ is equal to zero when $\gamma=0$, its derivative with respect to $\gamma$ evaluated at $\gamma=0$ is positive, and when $\gamma=1$, as $\eta$ grows large it eventually becomes negative. Hence, there exists a $\bar{\eta}>1$ such that for $\eta<\bar{\eta}(7)$ holds for all $j$ and $n$. In a similar way it can be shown that both high and low-type median voters prefer to elect a high-type when the majority is composed of high-types, and doing so will not change which type is in the majority.

Next, consider the preferences of a voter when other districts have elected $n$ high-types and $n$ low types, that is, when the voter is pivotal. Clearly, a high type median voter will always want to elect a high-type. By doing so she can shift the majority of the legislature in her favor and elect a high-type representative for her district. On the other hand, a low-type median voter will want to elect a low-type when her choice will be pivotal in shifting the majority of the legislature from high-types to low-types when $u_{l}(L \mid n L, n H) \geq u_{l}(H \mid n L, n H)$, that is:

$$
\left(\frac{\pi_{(n+1) H}^{H}}{\pi_{(n+1) L}^{L}}\right)^{\frac{\alpha}{1-\alpha}} \leq \frac{u_{l}\left(\tau_{l}^{*}\right)-y_{l}}{u_{l}\left(\tau_{h}^{*}\right)-y_{l}}
$$

which is the same as (4), and can be simplified to

$$
\left(\frac{(1-\gamma+\gamma \eta)(n(1-\gamma+\gamma \eta)+(n+1))}{(n+1)(1-\gamma+\gamma \eta)+n}\right)^{\frac{\alpha}{1-\alpha}} \leq \frac{\eta^{\frac{1}{1-\alpha}}(1-\alpha)}{\eta-\alpha}
$$

In the case of three districts, that is $n=1$, that minimizes the left hand side of the inequality, the condition further simplifies to

$$
\left(\frac{(1-\gamma+\gamma \eta)((1-\gamma+\gamma \eta)+2)}{2(1-\gamma+\gamma \eta)+1}\right)^{\frac{\alpha}{1-\alpha}} \leq \frac{\eta^{\frac{1}{1-\alpha}}(1-\alpha)}{\eta-\alpha}
$$

To show that $\gamma^{*}(n)<1$, we need to show that the above never holds when $\gamma=1$. In that 
case the expression simplifies further to:

$$
\left(\frac{\eta+2}{2 \eta+1}\right)^{\frac{\alpha}{1-\alpha}} \leq \frac{\eta(1-\alpha)}{\eta-\alpha}
$$

which never holds because, as shown above, in the case of $\gamma=1$ we have that $\eta<\bar{\eta}$ if and only if $(3 /(\eta+2))^{\frac{\alpha}{1-\alpha}}>(1-\alpha) /\left(\eta^{\alpha}-\alpha\right)$, so $((\eta+2) /(2 \eta+1))^{\frac{\alpha}{1-\alpha}}>(3 /(\eta+2))^{\frac{\alpha}{1-\alpha}}>$ $(1-\alpha) /\left(\eta^{\alpha}-\alpha\right)>\eta(1-\alpha) /(\eta-\alpha)$.

When (4) holds, then pure-strategy equilibria will have two forms. Either $n+1$ districts will elect low type legislators and $n$ districts will elect high-type legislators, or all $2 n+1$ districts will elect high type legislators.

Consider the first type. This is an equilibrium as anyone who is electing a high-type legislator is not pivotal, and thus would prefer to elect a high-type. Any median voter who is electing a low-type legislator is pivotal, so, as (4) holds, they prefer to elect a low-type.

Consider now the second type. This is an equilibrium as the median voter in every district is not pivotal, they prefer to elect a high type.

Now, we show there exist no other pure-strategy equilibria. Take as a candidate equilibrium one where $j<n$ districts elect high types, and the rest of the districts elect high-types. Then the median voter of every district that is electing a low-type is not pivotal, and would prefer to elect a high-type. Thus, this cannot be an equilibrium. Similar logic applies when the candidate equilibrium calls for $j^{\prime}<n$ districts to elect low types, and the rest to elect high-types.

Finally, we show that the equilibrium of the second type is not stage strong, but equilibria of the first type are. In the equilibrium of the second type the tax rate is $\tau_{h}^{*}$ and each district gets an equal share of tax revenue. It will be a profitable deviation for $n+1$ low-type districts to elect low-types if

$$
\left(\frac{\pi_{(2 n+1) H}^{H}}{\pi_{(n+1) L}^{L}}\right)^{\frac{\alpha}{1-\alpha}}<\frac{u_{l}\left(\tau_{l}^{*}\right)-y_{l}}{u_{l}\left(\tau_{h}^{*}\right)-y_{l}}
$$


As $\pi_{(2 n+1) H}^{H}=\frac{1}{3}<\pi_{(n+1) H}^{H}$, this implies that

$$
\left(\frac{\pi_{(2 n+1) H}^{H}}{\pi_{(n+1) L}^{L}}\right)^{\frac{\alpha}{1-\alpha}}<\left(\frac{\pi_{(n+1) H}^{H}}{\pi_{(n+1) L}^{L}}\right)^{\frac{\alpha}{1-\alpha}}<\frac{u_{l}\left(\tau_{l}^{*}\right)-y_{l}}{u_{l}\left(\tau_{h}^{*}\right)-y_{l}}
$$

as (4) holds. Thus, there is a profitable deviation for $n+1$ low types, and the equilibrium of the second type is not stage strong.

To see that all equilibria of the first type are stage strong, consider a potential deviation in which the low-type voters in $j$ of the districts that are supposed to elect low-type legislators (in equilibrium) instead defect and vote for, and elect, high-type legislators. This will be a profitable deviation if:

$$
\left(\frac{\pi_{(n+j) H}^{H}}{\pi_{(n+1) L}^{L}}\right)^{\frac{\alpha}{1-\alpha}}>\frac{u_{l}\left(\tau_{l}^{*}\right)-y_{l}}{u_{l}\left(\tau_{h}^{*}\right)-y_{l}} .
$$

However, as $\pi_{(n+j) H}^{H}<\pi_{(n+1) H}^{H}$, it follows from (4) that

$$
\left(\frac{\pi_{(n+j) H}^{H}}{\pi_{(n+1) L}^{L}}\right)^{\frac{\alpha}{1-\alpha}}<\left(\frac{\pi_{(n+1) H}^{H}}{\pi_{(n+1) L}^{L}}\right)^{\frac{\alpha}{1-\alpha}}<\frac{u_{l}\left(\tau_{l}^{*}\right)-y_{l}}{u_{l}\left(\tau_{h}^{*}\right)-y_{l}}
$$

so there is no coalition of low-type voters who were supposed to vote for low-type candidates who would be made strictly better off by voting for (and electing) high-type candidates. As high-type voters do not affect the outcomes in any district, we do not need to consider deviations by them.

Next, consider a deviation in which the low-type voters in $j^{\prime}$ districts that are supposed to elect high-type legislators (in equilibrium) instead defect and vote for, and elect, low-type legislators. Had these voters complied with their equilibrium strategies, they would have received:

$$
y_{l}+\left(\frac{\bar{y}}{y_{l}}\right)^{\frac{\alpha}{1-\alpha}} \frac{\left(\pi_{(n+1) L}^{L}\right)^{\frac{\alpha}{1-\alpha}}}{\alpha}\left(\left(\frac{\pi_{(n+1) L}^{H}}{\pi_{(n+1) L}^{L}}\right)^{\alpha}-\alpha\right)
$$

while deviating gives:

$$
y_{l}+\left(\frac{\bar{y}}{y_{l}}\right)^{\frac{\alpha}{1-\alpha}} \frac{\left(\pi_{\left(n+j^{\prime}+1\right) L}^{L}\right)^{\frac{\alpha}{1-\alpha}}}{\alpha}(1-\alpha)
$$


After substitutions, and noticing that the utility gain from sticking with the equilibrium strategy is minimized when $n=1, j^{\prime}=1$, we obtain the same condition (8) we derived earlier. Hence, the deviation will not be profitable as long as $\eta<\bar{\eta}$, which it is, by assumption. Thus, there is no coalition of low-type voters who were supposed to vote for high-type candidates who would be made strictly better off by voting for (and electing) low-type candidates. Note that none of the above relationships depend on the number of high-type median voters, $z$, which will always elect high-types in equilibria.

As all stage-strong equilibria are also equilibria, and we have identified all pure-strategy equilibria, we have thus identified all pure-strategy stage-strong equilibria when (4) holds.

When (4) does not hold, then electing a low-type legislator is strictly dominated, so every district will want to elect a high-type legislator. As such, this is the unique equilibrium. As the payoff to defection for low types is largest when they all defect to vote for a low-type legislator, this equilibrium will be stage strong when this deviation is not profitable for a low type. Specifically, if

$$
u_{l}(H \mid(2 n) H)-u_{l}(L \mid(2 n-z) L, z H)>0
$$

then the equilibria will be stage strong. Simplifying leads to the following conditions for stage-strong:

$$
\left(\frac{z \gamma(\eta-1)}{2 n+1}+1\right)^{\frac{\alpha}{1-\alpha}}>\frac{\eta^{\frac{1}{1-\alpha}}(1-\alpha)}{\eta-\alpha}
$$

which is the same as found in the proposition. To see that this condition is not redundant, that is, whenever the unrepresentative equilibrium is unique then it may or may not be stage-strong, notice that the right-hand-side of the latter inequality is equal to the right hand side of (4). Furthermore

$$
\text { LHS of }(4)=\left(\frac{(1-\gamma+\gamma \eta)(n(1-\gamma+\gamma \eta)+(n+1))}{(n+1)(1-\gamma+\gamma \eta)+n}\right)^{\frac{\alpha}{1-\alpha}}>\left(\frac{z \gamma(\eta-1)}{2 n+1}+1\right)^{\frac{\alpha}{1-\alpha}} \text {, }
$$

where the inequality follows from straightforward algebra. 


\section{Proposition 2.}

1. $\gamma^{*}(n)$ is decreasing in $n$. As $n \rightarrow \infty, \gamma^{*}(n) \rightarrow \kappa(\eta, \alpha)$, where $\kappa(\eta, \alpha) \in(0,1)$.

2. $\tau_{n}^{*}$ is decreasing in $n$.

Proof of Proposition 2; To show (1), note that $\gamma^{*}(n)$ is defined implicitly by (4), and that the RHS of that equation does not depend on $n$ or $\gamma$. Thus, by implicit differentiation we have that

$$
\begin{aligned}
& \frac{d \gamma^{*}(n)}{d n}=-\frac{d\left(\frac{\pi_{(n+1) H}^{H}}{\pi_{(n+1) L}^{L}}\right)^{\frac{\alpha}{1-\alpha}} / d n}{d\left(\frac{\pi_{(n+1) H}^{H}}{\pi_{(n+1) L}^{L}}\right)^{\frac{\alpha}{1-\alpha}} / d \gamma} \\
& \frac{d\left(\frac{\pi_{(n+1) H}^{H}}{\pi_{(n+1) L}^{L}}\right)^{\frac{\alpha}{1-\alpha}}}{d n}=\frac{\alpha}{1-\alpha}\left(\frac{\pi_{(n+1) H}^{H}}{\pi_{(n+1) L}^{L}}\right)^{\frac{2 \alpha-1}{1-\alpha}} \frac{\gamma(\eta-1)((1-\gamma)+\gamma \eta)(1+(1-\gamma)+\gamma \eta)}{((n+1)((1-\gamma)+\gamma \eta)+n)^{2}}>0 \\
& \frac{d\left(\frac{\pi_{(n+1) H}^{H}}{\pi_{(n+1) L}^{L}}\right)^{\frac{\alpha}{1-\alpha}}}{d \gamma}=\frac{\alpha}{1-\alpha}\left(\frac{\pi_{(n+1) H}^{H}}{\pi_{(n+1) L}^{L}}\right)^{\frac{2 \alpha-1}{1-\alpha}} \\
& \quad \times \frac{n(\eta-1)(2 n+2(n+1)+\gamma(\eta-1)(3 n+1+(n+1)((1-\gamma)+\gamma \eta)))}{((n+1)((1-\gamma)+\gamma \eta)+n)^{2}}>0
\end{aligned}
$$

thus $d \gamma^{*}(n) / d n<0$. As $n \rightarrow \infty$, then $\gamma^{*}(n)$ goes to:

$$
\gamma^{*}(n)=\frac{1}{\eta-1}\left[\left(\frac{1-\alpha}{\eta-\alpha}\right)^{\frac{\alpha}{1-\alpha}} \eta^{1 / \alpha}-1\right] \equiv \kappa(\eta, \alpha)
$$

which is clearly positive. Proposition 1 shows it is less than one.

The second point follows from the first and the discussion in the text.

\section{Proposition 3.}

1. $\gamma^{*}(q)$ is decreasing in $q$.

2. In unrepresentative equilibria, the average tax rate is increasing in $q$.

3. There exists a $\bar{q}>0$ such that for $q<\bar{q}$ expected taxes are lower in the unrepresentative equilibrium than in somewhat representative equilibria. 


\section{Proof of Proposition 3 ;}

To show the first part of the proposition we begin by characterizing $\gamma^{*}(q)$. Recall that $\gamma^{*}(q)$ is obtained by imposing that when the first and third district elect a low and high type, respectively, a low type median voter in the middle district is indifferent between electing a low type and high type. The difference with benchmark model, however, is that now a high type legislator will vote for tax rates as if he had low income with probability $q>0$. With slight abuse of notation, we will refer to this type as $\mathrm{Hl}$ and to the original high type in the benchmark model as $H h$. Hence, if the low type median voter in the middle district elects a high type legislator, he faces three scenarios. With probability $(1-q)^{2}$, the two $H h$-type legislators will set a tax equal to $\tau_{2 H h}^{*} \equiv\left(3 \pi_{2 H}^{H}\right)^{\frac{\alpha}{1-\alpha}} \tau_{h}^{*}$ as in equation $(5)$. With probability $q^{2}$, the two $H l$-type legislators have preferences for relatively high taxes, and will set a tax equal to $\tau_{2 H l}^{*} \equiv\left(3 \pi_{2 H}^{H}\right)^{\frac{\alpha}{1-\alpha}} \tau_{l}^{*}$. Finally, with probability $2 q(1-q)$, there is one $H h$-type and one $\mathrm{Hl}$-type (the first district legislator is a low type). Notice that in this latter case the $H l$-type legislator will always prefer a larger tax than the two other legislators (he prefers high taxes and can secure for its district a large proportion of revenues). As such, he will never be the median legislator. A necessary and sufficient condition for the low type to be median legislator when the other two legislators are one $H h$-type and one $H l$-type is therefore $\tau_{2 H h}^{*}<\left(3 \pi_{2 H}^{L}\right)^{\frac{\alpha}{1-\alpha}} \tau_{l}^{*}$, where the RHS of the inequality is the most preferred tax the low type in the legislature. The inequality can be rewritten as

$$
\frac{\left(3 \pi_{2 H}^{L}\right)^{\frac{\alpha}{1-\alpha}} \tau_{l}^{*}}{\left(3 \pi_{2 H}^{H}\right)^{\frac{\alpha}{1-\alpha}} \tau_{h}^{*}}=\left(\frac{\pi_{2 H}^{L}}{\pi_{2 H}^{H}}\right)^{\frac{\alpha}{1-\alpha}} \eta^{\frac{1}{1-\alpha}}=\left(\frac{1}{1-\gamma+\gamma \eta}\right)^{\frac{\alpha}{1-\alpha}} \eta^{\frac{1}{1-\alpha}}>1
$$

which is always verified since

$$
\left(\frac{1}{1-\gamma+\gamma \eta}\right)^{\frac{\alpha}{1-\alpha}} \eta^{\frac{1}{1-\alpha}}>\left(\frac{1}{\eta}\right)^{\frac{\alpha}{1-\alpha}} \eta^{\frac{1}{1-\alpha}}=\eta>1
$$


Combining results, we have that with $q>0$, (4) becomes:

$$
\left(\frac{\pi_{2 H}^{H}}{\pi_{2 L}^{L}}\right)^{\frac{\alpha}{1-\alpha}} \leq \frac{u_{l}\left(\tau_{l}^{*}\right)-y_{l}}{(1-q)^{2} u_{l}\left(\tau_{h}^{*}\right)+q^{2} u_{l}\left(\tau_{l}^{*}\right)+2 q(1-q) u_{l}\left(\frac{\tau_{l}^{*}}{((1-\gamma)+\gamma \eta)^{\frac{\alpha}{1-\alpha}}}\right)-y_{l}}
$$

which uniquely pins down $\gamma^{*}(q)$. Since the denominator of the RHS is increasing in $q, \gamma^{*}(q)$ is decreasing in $q$.

To establish the second point, fix $\gamma<\gamma^{*}(q=0)$. The tax rate in an unrepresentative equilibrium is $\tau_{h}^{*}$ with probability $(1-q)^{3}+3 q(1-q)^{2}$ and $\tau_{l}^{*}>\tau_{h}^{*}$ with probability $q^{3}+3 q^{2}(1-$

$q)$, whereas the tax rate in the somewhat representative equilibrium is $\left(3 \pi_{2 L}^{L}\right)^{\frac{\alpha}{1-\alpha}} \tau_{l}^{*} \in\left(\tau_{h}^{*}, \tau_{l}^{*}\right)$. Thus, when $q=0$ the tax rate is lower in the unrepresentative equilibrium, and when $q=1$ the tax rate is lower in somewhat representative equilibria. As the tax rate in somewhat representative equilibria is constant in $q$ (for fixed $\gamma$ ), whereas it is monotonically increasing in $q$ in the unrepresentative equilibria, there is some $\bar{q}$ such that for $q<\bar{q}$ the tax rate is lower in the unrepresentative equilibrium.

The third point follows from the fact that $q^{3}+3 q^{2}(1-q)>0$ when $q>0$.

\section{Proposition 4.}

1. If $0<\gamma<\gamma^{*}(n)<1$ then party $L$ nominates at least $n+1$ low-type candidates in districts with low-type median voters, and is otherwise indifferent. Party $H$ nominates $n$ high-type candidates, and is otherwise indifferent.

2. If $\gamma^{*}(n)<\gamma<1$ then party $H$ nominates high-type candidates in every district. Party $L$ is indifferent in all districts.

3. All patterns of representation and taxation continue to hold as in Proposition 1.

Proof of Proposition 4: It is straight-forward to show that, in equilibrium

$$
\tau_{h}^{*}<\tau_{(2 n) H}^{*}<\tau_{(2 n-1) H}^{*}<\cdots<\tau_{(n+1) H}^{*}<\tau_{(n+1) L}^{*}<\cdots<\tau_{(2 n-1) L}^{*}<\tau_{(2 n) L}^{*}<\tau_{l}^{*}
$$


thus, given the preferences of the $L$ and $H$ parties, they want to maximize the number of low-types and high-types, respectively, in office.

If $\gamma>\gamma^{*}(n)$, then every district would like to elect a high-type legislator. To ensure that one is elected in every district, party $H$ must nominate one in every district. If they did not, then the $L$ party would not either, and a low-type would be elected in that district. As party $L$ 's strategy does not affect the outcome, they are indifferent.

When $\gamma<\gamma^{*}(n)$, then suppose that both parties play in accordance with the equilibrium strategies described in part 1) of the proposition. Then $n+1$ low-type legislators and $n$ high-type legislators are being elected. To show that this describes all equilibria, we need to show that neither party can improve its outcome through deviating. First, suppose that party $L$ attempts to do so by getting another low-type legislator elected. The only way this could occur is if there is a district where party $H$ is nominating a low type, and party $L$ is nominating a high type who is being elected. By switching to a low-type candidate in that district, the district will be forced to elect a low-type candidate. However, because party $H$ has nominated $n$ high types, and at most $n-1$ of them are being elected (because in the district under consideration the high type was nominated by party $L$ ) there exists another district that wants to elect a high type, and can do so. So the deviation will not be profitable for party $L$.

Now, suppose party $H$ tries to change strategy and get an additional high-type legislator elected. There are two ways this could happen. First, a district with a low-type median voter could be electing a low-type from party $H$ with party $L$ nominating a high-type in that district. The reason this is not a profitable deviation for party $H$ follows the logic in the paragraph above. Second, a district with a high-type median voter is electing a low type because both parties are nominating a low types in the district. Party $H$ could switch to nominate a high type, who the district would then elect. However, at most $n$ of the $n+1$ low-type candidates nominated by party $L$ in districts with low-type median voters are winning. So there would be a district with a low-type median voter that would want to, and could, elect a low type, and would thus do so, ensuring that this is not a profitable 
deviation from the proposed equilibrium for either party. Similar arguments show that if either party nominated less low or high types then in the specified equilibria, they would be strictly better off by deviating to nominating all low or high types (respectively), showing we have identified all equilibria.

Part 3) follows from the argument above.

Proposition 5. If $0<\gamma<\gamma^{*}(n)$, then there exists some $\Delta_{\tau}^{*}$ such that when $\Delta_{\tau} \in$ $\left(\Delta_{\tau}^{*}, \tau_{(n+1) L}^{*}-\tau_{h}^{*}\right)$ then the tax rate and representation will be lower in equilibrium when parties can discipline their legislators than when they cannot.

Proof of Proposition 5: We begin by examining the response of low-type median voters to different candidate types, and then examine party strategies.

Suppose that a low-type median voter had a choice between a high type that who commits to act as if his ideal tax rate was $\tau_{h}^{*}+\Delta_{\tau}=\tau_{h}^{*}+\tau_{2 L}^{*}-\tau_{h}^{*}=\tau_{2 L}^{*}$, and a low type while the other two districts are electing a high type and a low type. The utility of voting for the high type is greater than voting for the low-type:

$$
\left(1-\tau_{2 L}^{*}\right) y_{l}+\frac{1}{\alpha}\left(\pi_{2 H}^{H} \tau_{2 L}^{*} \bar{y}\right)^{\alpha}>\left(1-\tau_{2 L}^{*}\right) y_{l}+\frac{1}{\alpha}\left(\pi_{2 L}^{L} \tau_{2 L}^{*} \bar{y}\right)^{\alpha}
$$

because $\pi_{2 H}^{H}>\pi_{2 L}^{L}$. As this is strictly greater, the low-type median voter would prefer to vote for a high type who commits to act as if his preferred tax rate is $\tau_{h}^{*}+\Delta_{\tau}$ as long as

$$
\left(1-\left(\tau_{h}^{*}+\Delta_{\tau}\right)\right) y_{l}+\frac{1}{\alpha}\left(\pi_{2 H}^{H}\left(\tau_{h}^{*}+\Delta_{\tau}\right) \bar{y}\right)^{\alpha} \geq\left(1-\tau_{2 L}^{*}\right) y_{l}+\frac{1}{\alpha}\left(\pi_{2 L}^{L} \tau_{2 L}^{*} \bar{y}\right)^{\alpha}
$$

where $\Delta_{\tau}^{*}$ is defined as the point of equality. Given that (4) is assumed to hold, without the ability to commit to $\tau_{h}^{*}+\Delta_{\tau}$, the tax rate would be $\tau_{2 L}^{*}$, so if $\Delta_{\tau} \in\left(\Delta_{\tau}^{*}, \tau_{2 L}^{*}-\tau_{h}^{*}\right)$, then the ability to commit will lower taxes.

If the commitment to implement a tax rate of $\tau_{h}^{*}+\Delta_{\tau}$ comes from a party, then Proposition 4, shows this will not change the structure of the equilibria. So what level of $\Delta_{\tau}$ 
would the parties choose? If $\Delta_{\tau} \in\left(\Delta_{\tau}^{*}, \tau_{2 L}^{*}-\tau_{h}^{*}\right)$, then the equilibrium is for the parties to nominate only high-types, and to commit their candidates to $\tau_{h}^{*}+\Delta_{\tau}$. If the low-type party committed to $\tau_{h}^{*}+\Delta_{\tau}^{\prime}<\tau_{h}^{*}+\Delta_{\tau}$, then the high party could deviate to the same platform and would be strictly better off, while the low-type party would be made strictly worse off.

\section{B Additional Results - Not Intended for Publication}

\section{B.1 Formal Treatment of Changing Institutions}

This subsection provides the technical details underlying the discussion of dynamic institutional change in Section 6.3 .

Under our definition of slow institutional change, $\gamma$ in the current period is set by the legislature in the previous period. Under fast institutional change, the current legislature is free to set $\gamma$ before any policy decisions are made. We define a period as a single iteration of our model with three legislative districts $(n=1)$, as in Section 3.2. Additionally, we assume that one district always has a high-type median voter $(z=1)$; we refer to this as the high district. A second district has a small probability, $1-p$, that the median voter there will be a high-type; we refer to this as the middle district. The type of the middle district's median voter is realized before the voting stage of each period. We also assume that all players have a common discount factor between periods of $\delta<1$.

We focus on Markov-perfect equilibria. To avoid issues of the state variable encoding entire histories, we restrict $\gamma$ to take on one of two values $\gamma \in\{0,1\}$. The state will thus include the type of the middle district's median voter, and the value of $\gamma$ at the beginning of the stage. We further assume that in the first period $\gamma=0$. Then we have:

Proposition 6. When institutional change is slow, then:

- If $\delta<\delta^{*}(p)$ then in each period the Markov-perfect equilibrium will be representative until the first period when the median voter of the middle district is a high type. Thereafter $\gamma=1$, and the equilibrium will be unrepresentative. 
- If $\delta>\delta^{*}(p)$ then the stage-strong, Markov-perfect equilibrium will be representative if the median voter of the middle district is a low type for at least two periods.

If institutional change is fast, then equilibria in each period will be representative.

Proof of Proposition 6: In order to consider the most interesting scenario, assume that at $\gamma=1, \eta$ is such that (4) does not hold. Let us first consider an equilibrium in which a hight-type median voter always elects a high-type legislator who will set $\gamma=1$ for the next period, and a low-type median voter always elects a low-type legislator who will set $\gamma=0$ for the next period. We can compute value functions for these strategies

$$
\begin{gathered}
V_{l}(L \mid L, H ; \gamma=0)=U_{l}(L \mid L, H ; \gamma=0)+\delta\left(p V_{l}(L \mid L, H ; \beta=1)+(1-p) V_{l}(H \mid L, H ; \gamma=0)\right) \\
V_{l}(H \mid L, H ; \gamma=0)=U_{l}(H \mid L, H ; \gamma=0)+\delta\left(p V_{l}(L \mid L, H ; \gamma=1)+(1-p) V_{l}(H \mid L, H ; \gamma=1)\right) \\
V_{l}(L \mid L, H ; \gamma=1)=U_{l}(L \mid L, H ; \gamma=1)+\delta\left(p V_{l}(L \mid L, H ; \gamma=0)+(1-p) V_{l}(H \mid L, H ; \gamma=0)\right) \\
V_{l}(H \mid L, H ; \gamma=1)=U_{l}(H \mid L, H ; \gamma=1)+\delta\left(p V_{l}(L \mid L, H ; \gamma=1)+(1-p) V_{l}(H \mid L, H ; \gamma=1)\right),
\end{gathered}
$$

and a low-type median voter will always elect a low-type legislator who will set $\beta=1$ if and only if

$$
V_{l}(L \mid L, H ; \gamma=1)>V_{l}(H \mid L, H ; \gamma=1)
$$

which implies

$$
V_{l}(L \mid L, H ; \gamma=0)>V_{l}(H \mid L, H ; \gamma=0)
$$

To save on notation, let

$$
\begin{gathered}
\Delta_{1} \equiv U_{l}(H \mid L, H ; \gamma=1)-U_{l}(L \mid L, H ; \gamma=1)=\left.\left(\frac{\bar{y}}{y_{l}}\right)^{\frac{\alpha}{1-\alpha}} \frac{\pi_{2 L}^{L \frac{\alpha}{1-\alpha}}(\eta-\alpha)}{\alpha \eta^{\frac{1}{1-\alpha}}}\left(\left(\frac{\pi_{2 H}^{H}}{\pi_{2 L}^{L}}\right)^{\frac{\alpha}{1-\alpha}}-\frac{u_{l}\left(\tau_{l}^{*}\right)-y_{l}}{u_{l}\left(\tau_{h}^{*}\right)-y_{l}}\right)\right|_{\gamma=1} \\
=\left(\frac{\bar{y}}{y_{l}}\right)^{\frac{\alpha}{1-\alpha}} \frac{(\eta-\alpha)}{\alpha(\eta+2)^{\frac{\alpha}{1-\alpha}} \eta^{\frac{1}{1-\alpha}}}\left(\left(\frac{\eta(\eta+2)}{2 \eta+1}\right)^{\frac{\alpha}{1-\alpha}}-\frac{\eta^{\frac{1}{1-\alpha}}(1-\alpha)}{\eta-\alpha}\right)>0 \\
\Delta_{2} \equiv U_{l}(L \mid L, H ; \gamma=0)-U_{l}(L \mid L, H ; \gamma=1)=\left(\frac{\bar{y}}{y_{l}}\right)^{\frac{\alpha}{1-\alpha}} \frac{1-\alpha}{\alpha(\eta+2)^{\frac{\alpha}{1-\alpha}}}\left(\left(\frac{\eta+2}{3}\right)^{\frac{\alpha}{1-\alpha}}-1\right)>0
\end{gathered}
$$


$\Delta_{3} \equiv U_{l}(H \mid L, H ; \gamma=0)-U_{l}(H \mid L, H ; \gamma=1)=\left(\frac{\bar{y}}{y_{l}}\right)^{\frac{\alpha}{1-\alpha}} \frac{\eta-\alpha}{\alpha 3^{\frac{\alpha}{1-\alpha}} \eta^{\frac{1}{1-\alpha}}}\left(1-\left(\frac{3 \eta}{2 \eta+1}\right)^{\frac{\alpha}{1-\alpha}}\right)<0$

Since at $\gamma=1$, (4) does not hold it follows that $\Delta_{1}<\Delta_{2}<-\Delta_{3}$. Furthermore, we have that $V_{l}(L \mid L, H ; \gamma=1)>V_{l}(H \mid L, H ; \gamma=1)$ if and only if

$$
\delta>\delta^{*}(p)=\frac{\Delta_{1}}{p \Delta_{2}+(1-p) \Delta_{3}} \text { and } p>p^{*}=\frac{\Delta_{1}-\Delta_{3}}{\Delta_{2}-\Delta_{3}}
$$

where $\delta^{*}\left(p^{*}\right)=1$ and $\delta^{*}(p)$ is decreasing in $p$ for $p \in\left(p^{*}, 1\right)$. Substituting, we get

$$
\delta>\delta^{*}(p)=\frac{\left(\frac{\eta(\eta+2)}{2 \eta+1}\right)^{\frac{\alpha}{1-\alpha}}-\frac{\eta^{\frac{1}{1-\alpha}}(1-\alpha)}{\eta-\alpha}}{p^{\frac{\eta^{1-\alpha}}{\eta-\alpha}}\left(\left(\frac{\eta+\alpha}{3}\right)^{\frac{\alpha}{1-\alpha}}-1\right)+(1-p)\left(\frac{\eta+2}{3}\right)^{\frac{\alpha}{1-\alpha}}\left(1-\left(\frac{3 \eta}{2 \eta+1}\right)^{\frac{\alpha}{1-\alpha}}\right)}
$$

and

$$
p>p^{*}=\frac{\left(\frac{3 \eta}{2 \eta+1}\right)^{\frac{\alpha}{1-\alpha}}-1}{\frac{\eta^{\frac{1}{1-\alpha}}(1-\alpha)}{\eta-\alpha}\left(1-\left(\frac{3}{\eta+2}\right)^{\frac{\alpha}{1-\alpha}}\right)-\left(\left(\frac{3 \eta}{2 \eta+1}\right)^{\frac{\alpha}{1-\alpha}}-1\right)}>\frac{1}{2}
$$

It is easy to check that a high-type median voter will always elect a high-type legislator who will set $\gamma=1$. Hence, when (9) holds, there is an equilibrium such that if the median voter of the middle district is a low-type, she will elect a low-type legislator, and the legislature will set $\gamma=0$ in the next period. Whenever the median voter of the middle district is a high type, she will elect a high-type legislator, and the legislature will set $\gamma=1$ in the next period. However, since $V_{l}(H \mid H, H ; \gamma=1)>V_{l}(L \mid H, H ; \gamma=1)$, there is also an equilibrium where the legislature will consist of two low types and a high type until the first period when the median voter of the middle district is a high type. Thereafter $\gamma=1$, and all three districts will elect high-types, who will set tax $\tau_{h}^{*}$. An argument similar to the one used in Proposition 1) is enough to conclude that only the former equilibrium is stage-strong.

When (9) is violated, $V_{l}(H \mid L, H ; \gamma=1)>V_{l}(L \mid L, H ; \gamma=1)$. Hence the legislature will consist of two low types and a high type and $\gamma$ will be equal to 0 until the first period when the median voter of the middle district is a high type. Thereafter $\gamma=1$, and all three 
districts will elect high-types, who will set $\operatorname{tax} \tau_{h}^{*}$. This equilibrium is stage-strong if and only if $V_{l}(H \mid H, H ; \gamma=1)>V_{l}(L \mid L, H ; \gamma=1)$, which is true for $\eta$ large enough, or $\delta$ small enough.

The result for fast institutional change follows immediately from the discussion in the text.

\section{B.2 Improving the Efficiency of Policy}

Another plausible explanation for the over-representation of high types in legislatures is that they are simply skilled at creating more efficient policy. In this subsection we consider this possibility, and show that while it would lead to an over-representation of high types, low types will generally comprise a minimal winning majority of the legislature.

To model this efficiency in our setting we can modify (1) to:

$$
u_{i j}=(1-\tau) y_{i}+\frac{\left(\kappa_{\operatorname{count}(\mathrm{H})} \pi \tau \bar{y}\right)^{\alpha}}{\alpha}
$$

with count $(\mathrm{H})$ the number of high-type legislators in the legislature, and $\kappa_{0}<\kappa_{1}<\cdots<$ $\kappa_{n}<\kappa_{n+1} \cdots<\kappa_{2 n+1}$. To explore the difference between this "quality" explanation, and our main focus - the ability to direct funds to one's district — we set $\pi=1 / 3$ for both highand low-type legislators.

The incentives given in Table 1 remain similar, and so does the structure of equilibria. In particular, high-type median voters will always want to elect high-type legislators as they have the same preferences and make government spending more valuable. A low-type median voter who knows that he will not be pivotal over the majority type in the legislature will also want to elect a high type as this will improve the utility of spending without lowering the tax rate. The only conflict comes when a low-type median voter knows that he is pivotal over the majority type in the legislature. In this case (4) will change to $\eta>\frac{\kappa_{n+1}}{\kappa_{n}}, 1$ To put

\footnotetext{
${ }^{1}$ If high types had both a "quality" difference and were better at targeting funds to their districts then
} 
this in concrete terms, if the income of the rich is three times that of the income of the poor, $\eta=3$, then in order for an unrepresentative equilibrium to obtain, the addition of a single high-type legislator would have to make the entire legislature at least three times more efficient. If this relative increase is constant, than a 435-member legislature will be $3.5 \times 10^{207}$ more efficient if composed only of high types versus only low types.2

This highlights the difference between a model in which high types convey a general "quality" difference in policymaking, and our model, in which high types are better at negotiating resources for their districts. In the former, because both efficiency and taxation are general policies that apply to everyone, the increase in efficiency has to be proportional to the decrease in taxes for low types to want to elect high types. This, in turn, has massive effects on general outcomes, in equilibrium. In the latter, ability at negotiating resources for one's district affects local outcomes much more than general outcomes. Thus, the negotiating advantage can be much smaller, and will not, in and of itself, affect equilibrium outcomes much: the broad effect comes through the prisoner's dilemma logic, discussed above.

\section{B.3 Low Types lead to More Efficient Spending}

Another avenue of exploration would be to examine what would happen if low-type legislators had an advantage in increasing the efficiency of taxation and spending, and high-type legislators had an advantage in directing funds to their districts. This can be modeled by recoding the model in Section $\mathrm{B} .2$ with $\kappa_{2 n+1}<\kappa_{2 n}<\cdots<\kappa_{n+1}<\kappa_{n} \cdots<\kappa_{0}$. The analogous condition to (4) would then be:

$$
\left(\frac{\kappa_{n+1} \pi_{(n+1) H}^{H}}{\kappa_{n} \pi_{(n+1) L}^{L}}\right)^{\frac{\alpha}{1-\alpha}}<\frac{u_{l}\left(\tau_{l}^{*}\right)-y_{l}}{u_{l}\left(\tau_{h}^{*}\right)-y_{l}}
$$

Given the logic in Section B.2, the ratio $\kappa_{n+1} / \kappa_{n}$ will be less than, but close to, one. As such, the condition will hold for slightly greater values of $\gamma$, leading to somewhat representative

this would reduce the cost to a low-type median voter of electing a high type, and thus the unrepresentative equilibrium would obtain for lower values of $\gamma$.

${ }^{2}$ Under such conditions $\tau=1$ even with few high-type legislators. 
equilibria for more values of $\gamma$. However, the unrepresentative equilibrium will now have less efficient government spending. Intuitively, this would be because $n+1$ low-type legislators, who can improve the efficiency of government spending, would be replaced by $n+1$ high-type legislators, who cannot.

\section{B.4 Baron-Ferejohn Bargaining}

The distribution between districts in Section 2.2.1 can be motivated using the bargaining model of Baron and Ferejohn (1989). Specifically, assume that high types are able to propose with higher probability, that is, proposal probabilities $p^{j}$ are given by

$$
p^{j}= \begin{cases}\frac{(1-\gamma)+\gamma * 1}{\sum_{j} p^{j}} & \text { if legislator } j \text { is a low type } \\ \frac{(1-\gamma)+\gamma * \eta}{\sum_{j} p^{j}} & \text { if legislator } j \text { is a high type. }\end{cases}
$$

Then, in the limit where legislators are very impatient, the expected share will be given by (3).$^{3}$ However, rather than this share being guaranteed, as it is in our core model, the legislator gets all of the tax revenue with probabilities given in (3). As such, this changes (4) to:

$$
\left(\frac{\pi_{2 H}^{H}}{\pi_{2 L}^{L}}\right)^{\frac{1}{1-\alpha}} \leq \frac{u_{l}\left(\tau_{l}^{*}\right)-y_{l}}{u_{l}\left(\tau_{h}^{*}\right)-y_{l}}
$$

As $\alpha \in(0,1), \frac{\alpha}{1-\alpha}<\frac{1}{1-\alpha}$, which implies that (4) will only hold for smaller values of $\gamma$ than in the core model. This occurs because the bargaining model introduces risk into the distributive process, which, given the concave utility of government spending, makes it more valuable to have a high-type legislator.

\section{B.5 More on Common Pool Problems}

In our model, the tax rate is strictly decreasing in the number of districts. However, this is due, in part, to the way we have modeled the utility of government spending: the functional

\footnotetext{
${ }^{3}$ Higher proposal power leads to higher expected shares only when legislators are sufficiently impatient, see Eraslan (2002).
} 
form implies spending is on local public goods. Thus, as districts become smaller, the effectiveness of this spending goes down. To remove this additional factor, and emphasize the role of the unrepresentative equilibrium in reversing the common pool problem, we thus examine a slightly different citizen utility function. That is, we replace (1) with:

$$
u_{i j}=(1-\tau) y^{i}+\frac{1}{\alpha}\left(\frac{\pi^{j} \tau \bar{y}}{1 /(2 n+1)}\right)^{\alpha}
$$

Then, defining $\tau_{n}^{*}$ as the tax rate implemented when there are $n$ legislators, we have:

Proposition 7. $\tau_{n}^{*}$ is decreasing in $n$ when citizen utility is given by (11).

Proof of Proposition 7: Using the utility function in (11) we have that

$$
\tau_{l}^{*}=\left(\frac{\bar{y}^{\alpha}}{y_{l}}\right)^{\frac{1}{1-\alpha}} \quad \text { and } \quad \tau_{h}^{*}=\left(\frac{\bar{y}^{\alpha}}{\eta y_{l}}\right)^{\frac{1}{1-\alpha}}=\frac{\tau_{l}^{*}}{\eta^{\frac{1}{1-\alpha}}}
$$

and that equilibria will be somewhat representative when

$$
\left(\frac{\pi_{(n+1) H}^{H}}{\pi_{(n+1) L}^{L}}\right)^{\frac{\alpha}{1-\alpha}} \leq \frac{u_{l}\left(\tau_{l}^{*}\right)-y_{l}}{u_{l}\left(\tau_{h}^{*}\right)-y_{l}}
$$

Note that the equilibrium tax rate in the minimally representative equilibria will be $((2 n+$ 1) $\left.\pi_{(n+1) L}^{L}\right)^{\frac{\alpha}{1-\alpha}} \tau_{l}^{*}$, which will be decreasing if $(2 n+1) \pi_{(n+1) L}^{L}$ is decreasing. Thus, to show this is true we have:

$$
\frac{d(2 n+1) \pi_{(n+1) L}^{L}}{d n}=\frac{d}{d n}\left(\frac{2 n+1}{n(1-\gamma+\gamma \eta)+(n+1)}\right)=\frac{\gamma(1-\eta)}{(n(1-\gamma+\gamma \eta)+(n+1))^{2}}<0 .
$$

We now turn our attention to the case where the equilibrium passes from minimally representative to unrepresentative as $n$ increases above $n^{*}$. At $n^{*}$ the condition for a minimally representative equilibrium gives

$$
\eta^{\frac{1}{1-\alpha}}\left(\pi_{\left(n^{*}+1\right) L}^{L}\right)^{\frac{\alpha}{1-\alpha}}=\left(\pi_{\left(n^{*}+1\right) H}^{H}\right)^{\frac{\alpha}{1-\alpha}} \frac{\eta-\alpha}{1-\alpha}
$$


and $\left(\left(2 n^{*}+1\right) \pi_{\left(n^{*}+1\right) L}^{L}\right)^{\frac{\alpha}{1-\alpha}} \tau_{l}^{*}>\tau_{h}^{*}$ if and only if

$$
\left(\left(2 n^{*}+1\right) \pi_{\left(n^{*}+1\right) L}^{L}\right)^{\frac{\alpha}{1-\alpha}}>\frac{1}{\eta^{\frac{1}{1-\alpha}}}
$$

or, if and only if

$$
\left(\frac{(1-\gamma+\gamma \eta)\left(2 n^{*}+1\right)}{\left(n^{*}+1\right) \beta(1-\gamma+\gamma \eta)+n^{*}}\right)^{\frac{\alpha}{1-\alpha}} \frac{\eta-\alpha}{1-\alpha}>1
$$

Note that

$$
\left(\frac{(1-\gamma+\gamma \eta)\left(2 n^{*}+1\right)}{\left(n^{*}+1\right)(1-\gamma+\gamma \eta)+n^{*}}\right)^{\frac{\alpha}{1-\alpha}} \frac{\eta-\alpha}{1-\alpha}>\frac{\eta-\alpha}{1-\alpha}>1
$$

as $\frac{(1-\gamma+\gamma \eta)\left(2 n^{*}+1\right)}{\left(n^{*}+1\right)(1-\gamma+\gamma \eta)+n^{*}}$ is increasing in $\gamma$, so is minimized at 1 when $\gamma=0$, and $\eta>1>\alpha$. Therefore, $\left(\left(2 n^{*}+1\right) \pi_{\left(n^{*}+1\right) L}^{L}\right)^{\frac{\alpha}{1-\alpha}} \tau_{l}^{*}>\tau_{h}^{*}$.

\section{B.6 Legislative Professionalization}

Many scholars have suggested that professionalization of legislatures may improve aggregate outcomes and the quality of government (see, for example Besley, 2007). In our model, increased professionalization through increased compensation creates a political class that has less in common with its constituents. Low- and high-type legislators in this class will have more in common with each other than their constituents, which will bias policy. If the political class is distinct enough, low-type median voters will opt for high-type legislators due to their superior negotiating abilities.

While it may seem reductionist to model increased professionalization through compensation, we note that even though legislative wages are nominally quite low, former legislators often go on to lucrative careers in lobbying or banking. Knowledge of these future wages may shape current preferences over taxes.4

Each legislator is paid a wage $\widetilde{w}=w y_{l}$, with $w>0$. This wage is in addition to the legislator's private sector earnings, and is subject to taxation. As legislators are citizen

\footnotetext{
${ }^{4}$ This may shape both their preferences over tax levels and types of taxes, see Section 7
} 
candidates, this wage will drive a wedge between the ideal tax rate of a legislator of a given type and a citizen of the same type. If this wage is high enough, low-type and high-type legislators' tax preferences will be similar. This will result in low-type voters favoring high types even when the difference in legislative ability is quite small. Given a legislative wage $w$, the ideal tax rates of low- and high-type legislators are:

$$
\tau_{l w}^{*}=\left(\frac{\bar{y}}{3\left((1+w) y_{l}\right)^{\frac{1}{\alpha}}}\right)^{\frac{\alpha}{1-\alpha}} \quad \tau_{h w}^{*}=\left(\frac{\bar{y}}{3\left((\eta+w) y_{l}\right)^{\frac{1}{\alpha}}}\right)^{\frac{\alpha}{1-\alpha}}
$$

The ideal tax rates of both types decrease with the legislative wage. This leads to the following result.

Proposition 8. If $\gamma>0$, and the legislative wage $w$ is high enough, then the unique equilibrium is unrepresentative with a tax rate $\tau_{h w}^{*}$.

Proof of Proposition 8: Reducing the right hand side of (12) to primitives we have:

$$
\frac{u_{l}\left(\tau_{l w}^{*}\right)-y_{l}}{u_{l}\left(\tau_{h w}^{*}\right)-y_{l}}=\frac{(1+w-\alpha)(\eta+w)^{\frac{1}{1-\alpha}}}{(\eta+w-\alpha)(1+w)^{\frac{1}{1-\alpha}}}
$$

and the limit of this quantity, as $w \rightarrow \infty$ is 1 , so for $w$ high enough, it will be less than the left-hand side (which is greater than 1), and thus, the unique equilibria will be the unrepresentative equilibrium. Furthermore, the left-hand side of (12) is greater than 1 for $\gamma>1$. Thus, as $w$ grows, the left-hand-side will eventually be less than the right-hand-side, which guarantees that (12) will not hold, and then all pure-strategy subgame-perfect equilibria will be as described in the second part of Proposition 1 .

To understand the intuition, note that a low-type median voter who is pivotal over the composition of the legislative majority will want to elect a low type when:

$$
\left(\frac{\pi_{2 H}^{H}}{\pi_{2 L}^{L}}\right)^{\frac{\alpha}{1-\alpha}} \leq \frac{u_{l}\left(\tau_{l w}^{*}\right)-y_{l}}{u_{l}\left(\tau_{h w}^{*}\right)-y_{l}} .
$$


Note that the left-hand side of (12) is greater than one, but as $w$ grows, the right-hand side converges to one. Thus, as $w$ grows, eventually 12 will not hold.

Globally, increasing legislative wages will make low-type citizens worse off, however, this may not be true locally. It is possible that $(12)$ does not hold at $w=0$, but does for a relatively small wage-leading to a somewhat representative, rather than unrepresentative, equilibrium. This occurs because when $w=0$, the numerator of the right-hand side of (12) is a low type's utility function at its maximal value (minus $y_{l}$, a constant). This implies that a small increase in the wage rate will not change the numerator at $w=0$, but it will decrease the denominator. Thus, increasing $w$ from zero may cause the equilibrium to change from unrepresentative, to somewhat representative, and then back to unrepresentative. Low-type utility is highest somewhere in range of parameters that lead to a somewhat representative equilibrium.

Overall, this suggests that there is a downside to paying legislators more: it will make them sufficiently different from the people they represent, resulting in lower taxation than the median voter prefers. Moreover, if the legislative wage is high enough, it will shrink the difference between all legislators sufficiently that low-type median voters, (correctly) view low- and high- type legislators as close enough substitutes on tax policy, and opt for the high-type legislator's superior ability to direct tax revenue to their district, depressing tax rates even further.

\section{B.6.1 Wages and Candidate Selection}

Most work that considers legislative professionalization has focused on the idea that it will attract better types - those with more human capital, perhaps - to political office. To take this into account, we use a crude model of candidate entry. In particular, we assume that in each district a single high-type candidate runs with independent probability $\rho(w)$, with $\rho^{\prime}(w)>0.5$ Lower wages will then make equilibria more representative:

\footnotetext{
${ }^{5}$ The usual justification for this reduced form - that those with higher skills have higher outside optionsdoes not hold in this case because legislators are assumed to continue to collect their private sector wages. However, assuming that high types value leisure more highly, for example, will lead to the same reduced
} 
Proposition 9. Suppose $\gamma$ is high enough so that (12) does not hold for any wage. Then, if a high type runs in any district, he will be elected. Thus:

1. The probability of a representative equilibrium is $(1-\rho(w))^{3}$.

2. If a high type is elected in any district, low types in other districts would be strictly better off if a high type ran in their district.

Proof of Proposition 9: As (12) does not hold, any district in which a high-type ran would elect a high type by Proposition 8, Part 1) is then immediate from the fact that with probability $(1-\rho(w))^{3}$ no high types run in any district, so low types are elected to the legislature, and set tax rate $\tau_{l}^{*}$.

Part 2) follows from the proofs of Proposition 1 and Proposition 8 . When (12) does not hold, then the equilibrium would be unrepresentative if high types ran in each district. The proof of Proposition 1 shows that in those conditions, each district strictly prefers to elect a high type legislator because it will improve the utility of the low types in that district.

The first part of the proposition is straightforward: if high types need wages to be convinced to run, and wages are low enough that no high types end up running, then all legislators will be low types. Moreover, if this is the case, then raising $w$ will only increase the probability of somewhat representative or unrepresentative equilibria as high types begin to run with increased frequency in all districts.

The second part is equally intuitive: if 12 does not hold, then according to the incentives in Table 1, low-type median voters in all districts would prefer to elect high types, implying that they would be better off with high-type representation. This shows a channel through which middling legislative wages may make low types worse off: once one district has a high-type legislator, then all low types would like to be represented by a high-type legislator. This reinforces the prisoner's dilemma logic discussed earlier, and can be seen as an "arms race" between low-type voters.

form.

Appendix-22 